\title{
Morphological and Molecular Identification of Two Florida Populations of Foliar Nematodes (Aphelenchoides spp.) Isolated From Strawberry With the Description of Aphelenchoides pseudogoodeyi sp. $\mathrm{n}$. (Nematoda: Aphelenchoididae) and Notes on Their Bionomics
}

\author{
Clemen J. Oliveira, ${ }^{1}$ Sergei A. Subbotin, ${ }^{2,3}$ Sergio Álvarez-Ortega, ${ }^{4}$ Johan Desaeger, ${ }^{5,}{ }^{\dagger}$ Janete A. Brito, ${ }^{6}$ Katia V. Xavier, \\ Leandro G. Freitas, ${ }^{1}$ Silvia Vau, ${ }^{6}$ and Renato N. Inserra ${ }^{6}$ \\ ${ }^{1}$ Department of Plant Pathology, Laboratory of Nematology, Viçosa, Federal University, Viçosa, MG, 36570-900, Brazil \\ ${ }^{2}$ Plant Pest Diagnostic Center, California Department of Food and Agriculture, Sacramento, CA 95832-1448, U.S.A. \\ ${ }^{3}$ Center of Parasitology of A.N. Severtsov Institute of Ecology and Evolution of the Russian Academy of Sciences, Leninskii \\ prospect 33, Moscow 117071, Russia \\ ${ }^{4}$ Department of Biology and Geology, Rey Juan Carlos University, Campus de Móstoles (Madrid), Spain \\ ${ }^{5}$ Department of Entomology and Nematology, Gulf Coast Research and Education Center, University of Florida, Wimauma, FL \\ 33598, U.S.A. \\ ${ }^{6}$ Florida Department of Agriculture and Consumer Services, DPI, Nematology Section, Gainesville, FL 32614-7100, U.S.A. \\ ${ }^{7}$ Department of Plant Pathology, Gulf Coast Research and Education Center, University of Florida, Wimauma, FL 33598, U.S.A.
}

\begin{abstract}
Two Florida populations of foliar nematodes were collected from strawberries originating from Cashiers, North Carolina (USA) located west from Willard, the type locality of Aphelenchoides besseyi. Both nematodes were cultured on Monilinia fructicola and identified using morphological characteristics and molecular assays as Aphelenchoides besseyi and Aphelenchoides pseudogoodeyi sp. n., a herein described new species related to Aphelenchoides goodeyi belonging to the Group of Aphelenchoides exhibiting stellate tails. The morphological and biological characters of Florida $A$. besseyi fit those of the original description of this species. A. pseudogoodeyi sp. n., which was initially misidentified as Aphelenchoides fujianensis, differed from the type population of the latter species from China because it was without

full-length 18S ribosomal RNA (rRNA), the D2-D3 expansion fragments of $28 \mathrm{~S}$ rRNA, and partial COI gene sequences indicated that A. besseyi is a species complex. A. pseudogoodeyi sp. $\mathrm{n}$. grouped in different clades from those of the type $A$. fujianensis, instead merging with populations identified of 'A. fujianensis' from Brazil and other countries, suggesting that the latter are conspecific and incorrectly identified. The Florida A. besseyi infected strawberry and gerbera daisy, but not soybean and alfalfa. A. pseudogoodeyi sp. n. is mainly mycetophagous. Localized inoculation of 300 specimens applied with filter paper adhering to the blade of the soybean leaves resulted in nematode penetration into the mesophyll with subsequent development of lesions limited to the inoculated area of the blade.
\end{abstract} males, and females lacked a functional spermatheca, whereas type $A$. fujianensis is an amphimictic species. Phylogenetic analyses using near
Keywords: etiology, fruit, pathogen diversity, small fruits
In Florida, infections of foliar nematodes, Aphelenchoides besseyi Christie, 1942, Aphelenchoides fragariae (Ritzema Bos 1890) Christie, 1932, and Aphelenchoides ritzemabosi (Schwartz 1911) Steiner $\&$ Buher, 1932 are common on many ornamental plants (Lehman 2002), but $A$. besseyi is the only species in this group of nematodes damaging to strawberries (Fragaria $\times$ ananassa) in the state. The symptoms that $A$. besseyi causes on strawberry are commonly known as "summer crimp disease." Christie (1959) proposed this epithet and reported that E. A. Bessey was the first to investigate and associate this disease with a nematode during field observations he conducted in North Carolina and Florida in 1901 and 1906, respectively. Subsequent studies by Brooks (1931) and Christie (1938) demonstrated and confirmed that the causal agent of this disease was a nematode, which was erroneously identified as Aphelenchus fragariae Ritzema Bos 1890, a nematode reclassified by Christie in 1932 as junior

${ }^{\dagger}$ Corresponding author: J. Desaeger; jad@ufl.edu

Funding: This project was funded in part by the Florida Strawberry Research and Education Foundation.

The author(s) declare no conflict of interest.

Accepted for publication 22 May 2019.

C 2019 The American Phytopathological Society synonym of Aphelenchoides fragariae, the spring dwarf nematode (for information regarding these taxonomical revisions see Filipjev 1934). The confusion in the identification arose because $A$. fragariae occurred on strawberry in Europe and northern areas of the United States. However, Christie (1942) clarified the identity of the species causing the summer crimp symptoms in North Carolina and Florida, describing it as a new species, $A$. besseyi, which was a prevalent damaging nematode on Florida strawberry from 1930 to the early 1950s. Afterward, the nematode infections were uncommon and not reported until 2016 when they reappeared in a few fields in central Florida (Desaeger and Noling 2017). Preliminary observations conducted in these fields indicated that different species of Aphelenchoides were present on declining strawberry plants. Three of these Aphelenchoides populations from strawberry in Florida were tentatively identified morphologically by Oliveira et al. (2018) as A. besseyi, Aphelenchoides bicaudatus (Filipjev and Schuurmans Stekhoven 1941; Imamura 1931) and Aphelenchoides fujianensis (Zhuo et al. 2010). However, the identities of these aphelenchoidids require more extensive morphological and molecular validation. Among the three species reported by Oliveira et al. (2018), A. besseyi and A. fujianensis belong to the same group of foliar nematodes with stellate tails (Shahina 1996) and can be confused in routine morphological diagnosis. These two similar species were reidentified in the results of this study as A. besseyi and Aphelenchoides pseudogoodeyi sp. n. A. bicaudatus is differentiated from the other two species by having the tail ending in a bifurcate tip (Siddiqui 1976) and was not included in our work. A. besseyi is a polyphagous facultative phytoparasite 
of rice, strawberry, and other plants (Christie 1959; Franklin and Siddiqi 1972). It is not known whether the Florida populations of putative $A$. besseyi can parasitize other economically important plants such as the forage legume alfalfa (Medicago sativa) that is damaged by Aphelenchoides rhitzemabosi in the Pacific Northwest of the United States (Gray et al. 1994), the flowering ornamental plant gerbera daisy (Gerbera jamesonii) that is parasitized by A. fragariae in Sri Lanka (Loos 1941), or the agronomic crop soybean (Glycine max) that is damaged by local populations of $A$. besseyi in Brazil (Favoreto and Meyer 2017; Favoreto et al. 2017). A. pseudogoodeyi sp. n. is related to A. fuijanensis, a mycetophogous species, being described from dead pine (Pinus massononiana) in China (Zhuo et al. 2010) and also identified in a study conducted in Brazil using populations from Brachiaria spp., Oryza sativa, and Phaseolus vulgaris seeds locally produced or imported from Costa Rica and Japan (De Jesus et al. 2016). The main objectives of this study were as follows: (i) to provide morphological characterization of the two Florida populations of Aphelenchoides and description of a new species named $A$. pseudogoodeyi sp. n.; (ii) to provide molecular characterization and phylogenetic relationships of these two Florida Aphelenchoides with other related populations using the $18 \mathrm{~S}$ ribosomal RNA (rRNA), D2-D3 of 28S rRNA, and partial COI gene sequences; and (iii) to determine their ability to infect alfalfa, gerbera daisy, soybean, and strawberry.

\section{Materials and Methods}

Nematode populations. The nematode populations used in this study were first collected on March 3, 2017, from strawberry plants, cultivar Florida Radiance, grown on a farm in Plant City, Hillsborough County, Florida. These plants were originally imported from a strawberry nursery located in Cashiers, North Carolina, and were showing distorted and crinkled leaves like those induced by foliar nematodes. The strawberry growing area of Cashiers is approximately 200 miles west of Willard, the type locality of A. besseyi. During this first sampling, the photosynthetic leaves of these infected plants were used to extract the nematode populations. These nematodes were identified as $A$. besseyi and maintained in a greenhouse on nematode-infected strawberry plants. An additional Aphelenchoides population was obtained later, at the end of the strawberry season, on 17 April 2017, from senescent and desiccated strawberry cultivar Florida Radiance leaves. This population, identified in this study as A. pseudogoodeyi sp. n., was maintained on desiccated strawberry plants in a greenhouse. Nematode samples were processed by incubating leaf fragments in water for $12 \mathrm{~h}$ (Young 1954). Specimens were hand-picked with an eye lash and transferred into a Syracuse watch glass. Five specimens having the same morphological characteristics were then placed in a 1-ml drop on 2week-old cultures of the fungus Monilinia fructicola (G. Winter) Honey growing in potato dextrose agar (BD Medical Technology, Sparks, MD). This fungus was selected as a culturing medium because it has been reported as a good host for many aphelenchs
(Giblin-Davis et al. 1989). Plates were incubated in the dark at $23^{\circ} \mathrm{C} \pm 3{ }^{\circ} \mathrm{C}$ for 23 days. At the end of the incubation period, a large portion of the nematodes that reproduced on fungus migrated on water drops condensed on the lid of the plates. These specimens free of fungal hyphae were transferred into watch glasses and used for morphological and molecular analyses and in experiments to determine their phytoparasitic habits. In addition, $A$. besseyi specimens reared on $M$. fructicola were used for comparison of their morphology with that of specimens extracted directly from strawberry.

Light microscopic study and morphological identification. Live adult specimens were hand-picked in water, immobilized by gentle heating, and mounted in $2 \%$ water agar (Fisher Scientific, Fair Lawn, NJ) (Esser 1986) on a slide for measurements and photographs. Additional specimens were processed and mounted in glycerin on permanent slides (Seinhorst 1959). Measurements of specimens were made using a Nikon (Tokyo, Japan) (Optiphot) ocular micrometer. Photographs were taken with a compound microscope, AXIO Scope A1 equipped with Nomarski interference contrast and an AxioCam ICc5 (Carl Zeiss, Göttingen, Germany). Measurements taken included those reported by Fortuner (1970) and Franklin and Siddiqi (1972) for Aphelenchoides species and additional ones used in taxonomic studies (Hunt 1993; Siddiqi 2000). The obtained characters of $A$. besseyi and A. pseudogoodeyi sp. n. were compared with those reported in the original description and redescriptions of $A$. besseyi, type A. fujianensis from China; 'A. fujianensis' populations identified by de Jesus et al. (2016) from Brazil, Costa Rica, and Japan; and other Aphelenchoides species with stellate tails sensu Shahina (1996).

DNA extraction, PCR amplification, and sequencing. Three specimens for each Aphelenchoides population were hand-picked and processed for DNA extraction (Floyd et al. 2002). DNA was used immediately for PCR. PCR amplifications were carried out using a thermocycler (Model T100; Bio-Rad, Hercules, CA) with a $50 \mu \mathrm{l}$ reaction volume consisting of $39.75 \mu \mathrm{l}$ of molecular water (HyClone, South Logan, UT), $5 \mu$ l of $10 \mathrm{X}$ ThermoPol reaction buffer, $1 \mu \mathrm{l}$ of deoxynucleotide (dNTPs) solution mix $(10 \mathrm{mM}), 1 \mu$ l each forward and reverse $10 \mu \mathrm{M}$ primer (Genewiz, South Plainfield, NJ), $0.25 \mu \mathrm{l}$ of Taq DNA polymerase (5000 U/m) (New England BioLabs, Ipswich, MA), and $2 \mu \mathrm{l}$ of DNA extract. The primer sets used in this study are listed in Table 1. Three different loci were amplified: (i) near full-length 18S RNA gene (SSU), (ii) the D2-D3 expansion fragments of $28 \mathrm{~S}$ rRNA gene, and (iii) partial COI gene. Amplified PCR products were resolved by electrophoresis at $70 \mathrm{~V}$ in $1 \%$ agarose gel, purified, and sequenced directly at Genewiz Company (Genewiz, South Plainfield, NJ). The nucleotide sequences obtained in this study were deposited in the GenBank database under accession numbers: MK291493 and MK291494 (18S rRNA gene); MK294342, MK564627, and MK294343 (28S rRNA gene); MK303401, MK559497, and MK303402 (COI gene).

Sequence and phylogenetic analyses. The newly obtained sequences for each gene (18S rRNA, D2-D3 of 28S rRNA, COI) were

Table 1. Primer sets, sequences, and PCR conditions used to amplify each gene in this study

\begin{tabular}{|c|c|c|c|c|c|c|c|c|c|}
\hline \multirow[b]{2}{*}{ Maker } & \multicolumn{2}{|r|}{ Primer } & \multirow{2}{*}{$\begin{array}{l}\text { In. Den } \\
\left({ }^{\circ} \mathrm{C}-\text { min }\right)\end{array}$} & \multicolumn{4}{|c|}{ Amplification $\left({ }^{\circ} \mathrm{C}-\mathrm{sec}\right)^{\mathrm{y}}$} & \multirow{2}{*}{$\begin{array}{l}\text { Final Ext } \\
\left({ }^{\circ} \mathrm{C}-\text { min }\right)\end{array}$} & \multirow[b]{2}{*}{ Reference } \\
\hline & Name & Sequence $\left(5^{\prime}\right.$ to $\left.3^{\prime}\right)$ & & Den & Ann & Ext & $\overline{\mathrm{Cyc}}$ & & \\
\hline \multirow[t]{2}{*}{$\overline{\mathrm{COI}}$} & COI-F & CCTACTATGATTGGTGGTTTTGGTAATTG & $94-5$ & $94-30$ & $51-30$ & $68-120$ & 42 & $68-10$ & $\overline{\text { Kanzaki and Futai } 2002}$ \\
\hline & COI-R & GTAGCAGCAGTAAAATAAGCACG & & & & & & & \\
\hline \multirow[t]{2}{*}{ D2-D3 } & $\mathrm{D} 2 \mathrm{~A}$ & ACAAGTACCGTGAGGGAAAGT & $95-5$ & $94-30$ & $55-45$ & $68-120$ & 35 & $68-10$ & Nunn 1992 \\
\hline & D3B & TCGGAAGGAACCAGCTACTA & & & & & & & \\
\hline \multirow[t]{6}{*}{$18 \mathrm{~S}^{\mathrm{z}}$} & 1813_F & CTGCGTGAGAGGTGAAAT & $94-5$ & $94-30$ & $45-30$ & $68-70$ & 5 & & Holterman et al. 2009 \\
\hline & 2646_R & GCTACCTTGTTACGACTTTT & & & & & & & \\
\hline & 988_F & CTCAAAGATTAAGCCATGC & & $94-30$ & $54-30$ & $68-70$ & 35 & $68-5$ & \\
\hline & $1912 \_\mathrm{R}$ & TTTACGGTCAGAACTAGGG & & & & & & & \\
\hline & 988_F & CTCAAAGATTAAGCCATGC & $95-2$ & $95-60$ & $55-90$ & $68-120$ & 40 & $68-5$ & Holterman et al. 2009 \\
\hline & 18SR-Burs & CTACGGCTACCTTGTTACGACTTTT & & & & & & & Ye et al. 2007 \\
\hline
\end{tabular}

\footnotetext{
y PCR conditions for amplifications: Initial denaturation (In. Den), denaturation (Den), annealing (Ann), Extension (Ext), and cycle quantity (Cyc).
}

${ }^{\mathrm{z}}$ DNA was amplified as two partially overlapping fragments. 
aligned using ClustalX 1.83 (Thompson et al. 1997) with their corresponding published gene sequences (Chizhov et al. 2006; de Jesus et al. 2016; Esmaeili et al. 2016; Sánchez-Monge et al. 2017; Wang et al. 2019; Zhuo et al. 2010). Outgroup taxa for each dataset were chosen based on previously published data (de Jesus et al. 2016, Sánchez-Monge et al. 2017). The best fit model of DNA evolution was obtained using the program jModeltest 0.1.1 (Posada 2008) under the Akaike information criterion. The general time reversible substitution model with estimation of invariant sites and assuming a gamma distribution with four categories $(\mathrm{GTR}+\mathrm{I}+\mathrm{G})$ was selected as the optimal nucleotide substitution model for the analyses of three genes. Sequence alignments were analyzed with Bayesian inference (BI) using MrBayes 3.1.2 (Ronquist and Huelsenbeck 2003; Ronquist et al. 2012). BI analysis for each gene was initiated with a random starting tree and was run with four chains for $2.0 \times 10^{6}$ generations. Two runs were performed for each analysis. The Markov chains were sampled at intervals of 100 generations. After discarding burn-in samples (10\%), a 50\% majority rule consensus tree was generated. Posterior probabilities (PP) in percentage are given on appropriate clades. Sequence analyses of alignments were performed with PAUP* 4b10 (Swofford 2003). Pairwise divergences between taxa were computed as absolute distance values and as percentage mean distance values based on whole alignment, with adjustment for missing data.

Phytoparasitic habits. Pregerminated seeds of alfalfa, gerbera daisy, and soybean cultivar Patriot were sown in individual $15-\mathrm{cm}-$ diameter plastic pots containing $1,700 \mathrm{~cm}^{3}$ of a growing mix (Metro-Mix 380; Sungro Horticulture, Agawam, MA) containing fine bark, perlite, vermiculite, Canadian sphagnum, and peat moss. Three-centimeter-long stolons rather than seeds were used for obtaining strawberry cultivar Florida Radiance plantlets. Before inoculation, seedlings of alfalfa and soybean grew for 15 days, whereas those of gerbera daisy and the strawberry stolons for 30 and 25 days, respectively. A single inoculum level of approximately 600 specimens per plant was used for $A$. besseyi because this density is higher than the standard density (400 specimens) used previously in successful inoculations (Marlatt and Perry 1971). Smaller and greater levels of inoculum (approximately 400 and 1,000 specimens) were chosen for A. pseudogoodeyi sp. n., because its host range and potential phytoparasitism are not known. The inoculations were carried out by pipetting the aqueous suspension of the nematodes at each concentration in multiple 1-ml droplets delivered slowly on the crowns of the alfalfa and strawberry plantlets and on the leaves of gerbera daisy and soybean seedlings to contain loss of the inoculum leaking in the soil (Fig. 1A). Localized inoculations, described in the following section, were conducted with A. pseudogoodeyi $\mathrm{sp}$. n. on soybean (Fig. 1B) with the aim of verifying the potential phytoparasitism, if any, of this species. The inoculation of the leaves rather than soil was used because the leaves of some of the selected plant species did not touch the soil and would have escaped the nematode infection from the inoculum in the soil. Studies conducted by Marlatt (1970) and Marlatt and Perry (1971) showed that $A$. besseyi is not able to climb the stem of Ficus elastica seedlings from the soil but is able to invade the leaves contacting the soil of the grass Sporobolus poiretii, indicating that the nematodes should be in contact with plant parts to initiate infection. Plant species were set up in a complete randomized design in a greenhouse with five replications. All plants were harvested 60 days after inoculation (DAI), except those of gerbera daisy inoculated with $A$. pseudogoodeyi sp. n. that were harvested 84 DAI. Development of above-ground symptoms was monitored 3 to 4 times per week. In addition, just for soybean, an extra set of five seedlings was inoculated each with approximately 1,000 specimens of $A$. pseudogoodeyi $\mathrm{sp}$. $\mathrm{n}$. to assess nematode survival on desiccated stem tissues of senescent plants 130 DAI. At harvest, above-ground plant weights were recorded and nematode per plant top and $200 \mathrm{~cm}^{3}$ soil were determined. Final population densities in the entire plant top tissues were determined by incubating in water the entire macerated plant top tissues (Young 1954) and are expressed as total number of nematodes found in the entire plant top. The final population densities of the soybean set harvested
130 DAI were expressed as number of nematodes per gram of desiccated stem tissues. Final soil densities were obtained using the "salad bowl" incubation method (Rodríguez-Kábana and Pope 1981). To avoid the interference of potential infestations of noxious arthropods, such as mites and thrips, on the symptoms induced by both nematode species, the experiment was repeated using a set of strawberry plantlets inoculated with $A$. besseyi and two sets of alfalfa and soybean seedlings inoculated with $A$. pseudogoodeyi sp. n. These plants were enclosed in cages screened with a $4-\mu \mathrm{m}$-pore net and kept in a randomized design in a greenhouse for 60 days. Five noninoculated plants for each species served as controls. Final nematode population densities were assessed as in the previous experiment and shown as repeated treatments. Nonparametric Kruskal-Wallis one-way analysis of variance on median ranks of the final nematode population densities was performed using R Core Team (2017).

Temperature $(\mathrm{T})$ and humidity $(\mathrm{RH})$ in the greenhouse were recorded using Hobo ProV2 onset (Onset Computer Corporation, Bourne, MA). For the test conducted using uncaged plants and extra sets of soybean seedlings, $\mathrm{T}$ and $\mathrm{RH}$ recorded were, respectively, maximum $42.5^{\circ} \mathrm{C}$ to minimum $12.8^{\circ} \mathrm{C}$ (average $23.8^{\circ} \mathrm{C}$ ) and maximum $100 \%$ to minimum $35.1 \%$ (average $88.5 \%$ ). The randomized plants on a greenhouse bench received nebulized water delivered for $3 \mathrm{~min}$, at intervals of $6 \mathrm{~h}$ from an automatic overhead irrigation system. For tests carried out using caged plants, T and RH were, respectively, maximum $46.2^{\circ} \mathrm{C}$ to minimum $20.8^{\circ} \mathrm{C}$ (average $29.5^{\circ} \mathrm{C}$ ) and maximum $100 \%$ to minimum $28.6 \%$ (average $82.1 \%$ ). The randomized plants on a bench received nebulized water delivered by hand with a sprayer twice per day.

Localized inoculation of $A$. pseudogoodeyi sp. n. on soybean leaves. Potential penetration into leaf tissues by this nematode and development of symptoms of infection in soybean seedlings were determined by applying paper filter pieces containing 300 specimens of the nematode on selected portions of the upper surface of all leaf blades as described by Riedel (1985) (Fig. 1B). Soybean seedlings were selected for this experiment because of the glabrous surface of their leaves that would have favored nematode penetration and development in the leaf tissues. The plants with attached pieces of filter paper on their leaves were enclosed in plastic bags and kept for $48 \mathrm{~h}$ in a cabinet in the dark at room temperature. After removal of the plastic bags, they were kept in a greenhouse for 4 weeks and irrigated with nebulized water delivered by hand with a sprayer twice per day. The inoculated leaves were examined for development of

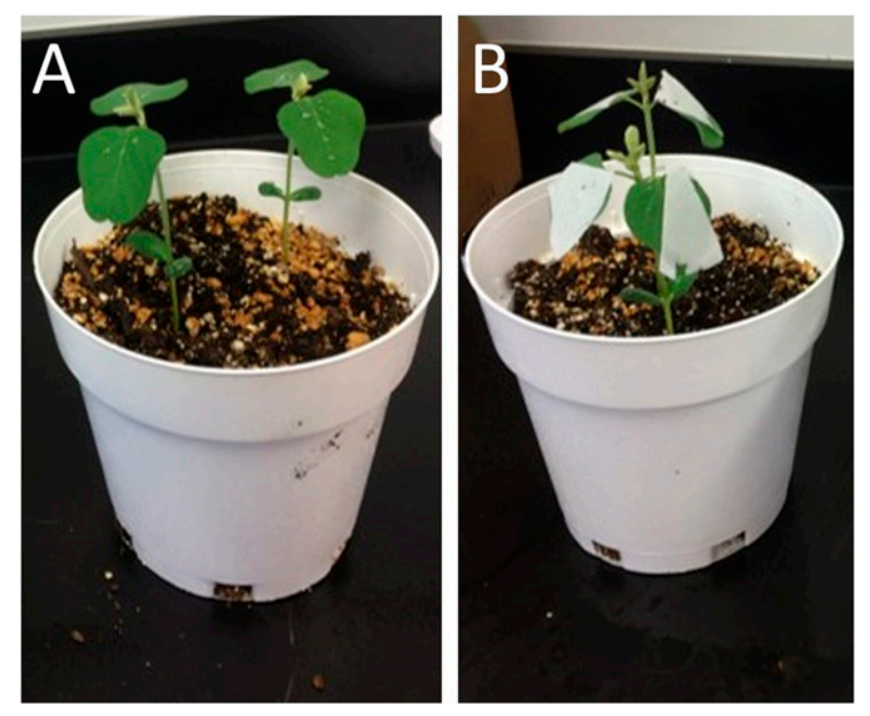

Fig. 1. Soybean seedlings inoculated with Aphelenchoides pseudogoodeyi sp. $\mathrm{n}$. using two techniques. A, Seedlings showing the upper surface of the leaf blade partially covered by droplets of the aqueous suspension of the nematodes delivered with a pipette. B, Seedlings showing pieces of filter paper containing the nematodes attached to the upper surface of the leaf blades. 
symptoms three to four times per week and at the end of the experiment using a stereomicroscope. Nematode penetration into the leaf tissues was verified by tearing the epidermis of the symptomatic leaves with a needle to observe and photograph nematode specimens in the mesophyll as mentioned previously.

\section{Results}

Light microscopic study and morphological identification. Morphological examination of the A. besseyi populations obtained directly from photosynthetic strawberry leaves and $M$. fructicola cultures indicated that these populations belong to the species $A$. besseyi, as reported by Oliveira et al. (2018). The morphometrics of the two populations (Table 2) were similar and did not differ from those reported in the original description by Christie (1942) or from those of a population from rice (Oryza sativa) by Fortuner (1970). Many morphometrics were missed in the original description of Christie (1942). Thus, the morphometrics obtained for the A. besseyi populations studied here also were compared with those reported by Allen (1952) and Franklin and Siddiqi (1972) for other populations of $A$. besseyi. The morphological features of females of the two samples, one from leaves and another from $M$. fructicola matched those of A. besseyi. The studied specimens from photosynthetic strawberry leaves and fungal plates had a stylet $12(11.5-12.5) \mu \mathrm{m}$ and 11 (10.9-11.2) $\mu \mathrm{m}$ long, respectively, like that reported by Fortuner (1970) $(10-12.5 \mu \mathrm{m})$ from the rice population. Stylet knobs or swellings were $2(1.9-2.2) \mu \mathrm{m}$ and $1.9(1.8-2) \mu \mathrm{m}$ wide for the specimens from plant tissues and fungus, respectively, and slightly larger than the average value of $1.75 \mu \mathrm{m}$ reported by Franklin and Siddiqi

Table 2. Morphometrics of live females and males of a Florida population of Aphelenchoides besseyi from strawberry and from Monilinia fructicola cultures compared with those in the original description by Christie (1942) and a redescription by Fortuner (1970)

\begin{tabular}{|c|c|c|c|c|c|c|c|c|}
\hline \multirow[b]{2}{*}{ Character $^{\mathrm{z}}$} & \multicolumn{2}{|c|}{ Strawberry (N17-00341) } & \multicolumn{2}{|c|}{ Monilinia fructicola (N18-01001-2) } & \multicolumn{2}{|c|}{$\begin{array}{c}\text { Strawberry } \\
\text { Christie (1942) }\end{array}$} & \multicolumn{2}{|c|}{ Rice Fortuner (1970) } \\
\hline & Female & Male & Female & Male & Female & Male & Female & Male \\
\hline$n$ & 15 & 2 & 10 & 10 & - & - & - & - \\
\hline $\mathrm{L}$ & $657.0 \pm 75.9(516.8-810.8)$ & $525.3 \pm 36.9(499.2-551.4)$ & $710.3 \pm 23.6(669.3-747.3)$ & $572.3 \pm 19.4(538.5-592.0)$ & $-(660-750)$ & $-(660-750)$ & $681(570-840)$ & $618(570-840)$ \\
\hline$a$ & $41.7 \pm 3.8(34.0-49.7)$ & $35.2 \pm 0.5(34.8-35.6)$ & $50.3 \pm 2.4(45.3-53.3)$ & $36.1 \pm 1.6(33.2-38.7)$ & $-(32-42)$ & $-(32-42)$ & $47.7(39.3-53.5)$ & $47.7(39.3-53.4)$ \\
\hline$b$ & $9.8 \pm 0.6(8.6-11.2)$ & $8.7 \pm 0.6(8.3-9.1)$ & $10.3 \pm 0.2(10.0-10.6)$ & $9.0 \pm 0.3(8.5-9.5)$ & $-(11.2-11.4)$ & - & $11.4(9.2-13.1)$ & $11.5(9.2-13.3)$ \\
\hline$b^{\prime}$ & $4.4 \pm 0.2(4.0-4.6)$ & $4.2 \pm 0.6(3.8-4.7)$ & $4.3 \pm 0.1(4.1-4.5)$ & $4.3 \pm 0.3(3.9-4.8)$ & - & - & $4.8(4.0-5.7)$ & $4.8(4-5)$ \\
\hline$c$ & $16.6 \pm 1.2(14.8-19.1)$ & $17.6 \pm 0.6(17.2-18.0)$ & $17.6 \pm 0.8(16.1-18.9)$ & $17.7 \pm 0.8(16.0-19.1)$ & $-(17-20)$ & $-(17-20)$ & $17.7(13.8-20.4)$ & $17.9(16.6-20.0)$ \\
\hline$c^{\prime}$ & $3.9 \pm 0.3(3.6-4.7)$ & $2.7-$ & $4.0 \pm 0.2(3.8-4.4)$ & $2.7 \pm 0.1(2.5-2.8)$ & - & - & - & - \\
\hline Max. body diameter & $15.7 \pm 1.3(13.3-17.8)$ & $14.9 \pm 1.3(14.0-15.8)$ & $14.1 \pm 0.6(13.4-15.2)$ & $15.9 \pm 0.4(14.9-16.3)$ & - & - & - & - \\
\hline $\begin{array}{l}\text { Body diameter } \\
\text { at anus or cloacal } \\
\text { opening distance }\end{array}$ & $9.9 \pm 0.7(8.9-11.4)$ & $10.7 \pm 0.3(10.5-11.0)$ & $9.8 \pm 0.5(9-11)$ & $12.0 \pm 0.3(11.5-12.5)$ & - & - & - & - \\
\hline$V$ & $70.5 \pm 0.5(69.7-71.6)$ & - & $69.8 \pm 0.6(68.8-70.8)$ & - & $-(68-70)$ & - & $71.2(68.7-73.6)$ & - \\
\hline OV or Testis/L\% & $26.8 \pm 2.5(23.2-31.1)$ & $52.5 \pm 16.2(41-64)$ & $25.9 \pm 1.1(24.3-27.6)$ & $44.2 \pm 4.2(38.0-51.4)$ & - & - & $27.9(19.9-39.3)$ & $40.6(28.2-52.3)$ \\
\hline $\begin{array}{l}\text { Anterior genital } \\
\text { tract length }\end{array}$ & $181.3 \pm 19.2(155.4-216.8)$ & $279.2 \pm 104.9(205.0-353.4)$ & $184.1 \pm 9.7(163-196)$ & - & - & - & - & - \\
\hline Lip region width & $6.9 \pm 0.3(6.0-7.5)$ & $6.5-$ & $6.9 \pm 0.1(6.7-7.0)$ & $6.6 \pm 0.1(6.4-6.8)$ & - & - & - & - \\
\hline Lip region height & $3.1 \pm 0.2(2.8-3.4)$ & $2.8 \pm 0.1(2.7-2.9)$ & $3-$ & $3-$ & - & - & - & - \\
\hline Stylet length & $12.0 \pm 0.2(11.5-12.5)$ & 12 - & $11.0 \pm 0.1(10.9-11.2)$ & $10.7 \pm 0.2(10.4-11.0)$ & - & - & $11.9(10.0-12.5)$ & $11.4(10.0-12.5)$ \\
\hline Stylet cone length & $6.7 \pm 0.3(6.2-7.0)$ & $6.8-$ & $5.0 \pm 0.1(5.0-5.2)$ & $5.0 \pm 0.1(4.8-5.0)$ & - & - & - & - \\
\hline Stylet knob height & $1.7 \pm 0.1(1.5-1.9)$ & $1.7-$ & $1.6 \pm 0.1(1.5-1.7)$ & $1.5 \pm 0.1(1.4-1.6)$ & - & - & - & - \\
\hline Stylet knob width & $2.0 \pm 0.1(1.9-2.2)$ & $2.3-$ & $1.9 \pm 0.1(1.8-2.0)$ & $1.9(1.8-1.9)$ & - & - & - & - \\
\hline Metacorpus length & $14.3 \pm 0.6(13.3-15.5)$ & $13.2 \pm 0.5(13-13.5)$ & $14.5 \pm 0.5(14.0-15.2)$ & $14.3 \pm 0.4(14-15)$ & - & - & - & - \\
\hline Metacorpus width & $10.0 \pm 0.5(9.2-11.0)$ & $9.5 \pm 0.7(9-10)$ & $9.9 \pm 0.4(9.0-10.5)$ & $10.0 \pm 0.3(9.5-10.6)$ & - & - & - & - \\
\hline $\begin{array}{l}\text { Metacorpus valve } \\
\text { length }\end{array}$ & $3.0 \pm 0.1(2.9-3.3)$ & $3.3 \pm 0.3(3.1-3.5)$ & $3.3 \pm 0.3(3.0-3.8)$ & $3.2 \pm 0.2(3.0-3.5)$ & - & - & - & - \\
\hline $\begin{array}{l}\text { Metacorpus valve } \\
\text { width }\end{array}$ & $2.0 \pm 0.2(1.9-2.5)$ & 2.1- & $2.6 \pm 0.1(2.5-2.8)$ & $2.4 \pm 0.1(2.3-2.5)$ & - & - & - & - \\
\hline Pharynx length & $66.9 \pm 4.8(59.0-73.2)$ & $66.9 \pm 4.8(59.0-73.2)$ & $68.4 \pm 1.4(66.3-70.3)$ & $63.3 \pm 1.5(61.4-66.8)$ & - & - & - & - \\
\hline $\begin{array}{l}\text { Pharyngeal overlap } \\
\text { length }\end{array}$ & $85.7 \pm 1.0(69.3-103.9)$ & $60-$ & $95.0 \pm 8.7(85-105)$ & $69.2 \pm 8.1(60.0-84.1)$ & - & - & - & - \\
\hline $\begin{array}{l}\text { Anterior end to } \\
\text { pharyngeal } \\
\text { gland lobe } \\
\text { distance }\end{array}$ & $151.8 \pm 13.9(129.0-176.2)$ & $122.8 \pm 10.5(115.4-130.3)$ & $162.9 \pm 7.4(152.0-172.3)$ & $133.1 \pm 9.5(121.4-150.4)$ & - & - & - & - \\
\hline $\begin{array}{l}\text { Anterior end to } \\
\text { excretory } \\
\text { pore distance }\end{array}$ & $80.1 \pm 6.8(68-93)$ & $68-$ & $79.4 \pm 3.7(75.0-86.1)$ & $76.2 \pm 3.0(70.3-81.2)$ & - & - & - & - \\
\hline $\begin{array}{l}\text { Post uterine sac } \\
\text { (PUS) length }\end{array}$ & $44.6 \pm 6.6(32.6-56.4)$ & - & $45.6 \pm 5.7(37.0-56.4)$ & - & - & - & - & - \\
\hline $\begin{array}{l}\text { Vulva anus } \\
\text { distance }\end{array}$ & $152.2 \pm 16.9(123.8-182.2)$ & - & $174.0 \pm 5.7(161.3-182.2)$ & - & - & - & - & - \\
\hline $\begin{array}{l}\text { Anterior end to } \\
\text { vulva distance }\end{array}$ & $464.1 \pm 54.4(360.4-574.2)$ & - & $496 \pm 19(468.3-529.6)$ & - & - & - & - & - \\
\hline $\begin{array}{l}\text { Posterior end to } \\
\text { vulva distance }\end{array}$ & $193.0 \pm 21.7(156.4-236.6)$ & - & $214.2 \pm 6.1(201.0-223.3)$ & - & - & - & - & - \\
\hline Tail length & $39.4 \pm 3.9(33.6-46.5)$ & $29.7 \pm 1.0(29.0-30.5)$ & $40.2 \pm 1.8(38.0-42.6)$ & $32.4 \pm 1.1(30.2-33.6)$ & - & - & - & $19.2(18-21)$ \\
\hline Spermatheca length & $38.4 \pm 9.5(33.6-46.5)$ & - & $58.0 \pm 5.4(49.5-69.3)$ & - & - & - & - & - \\
\hline Spermatheca width & $8.1 \pm 0.6(7.0-9.5)$ & - & $8.2 \pm 1.1(6-10)$ & - & - & - & - & - \\
\hline Spicule length & - & $18.1 \pm 0.9(17.5-18.8)$ & - & $18.3 \pm 0.7(17.0-19.3)$ & - & - & - & - \\
\hline $\begin{array}{l}\text { Gubernaculum } \\
\text { length }\end{array}$ & - & - & - & - & - & - & - & - \\
\hline PUS/VA \% & $29.3 \pm 3.6(21.9-33.7)$ & - & $26.4 \pm 3.7(20.7-31.8)$ & - & - & - & - & - \\
\hline Lateral field width & $3.8 \pm 0.4(3.5-4.5)$ & - & $3.2 \pm 0.1(3.0-3.5)$ & - & - & - & - & - \\
\hline Spikes length & - & $2-$ & - & - & - & - & - & $-(2-3)$ \\
\hline Testis length & - & - & - & $253.1 \pm 27.8(213.8-300.1)$ & - & - & - & - \\
\hline $\begin{array}{l}\text { Post uterine sac } \\
\text { length/Body } \\
\text { length }\end{array}$ & $6.7 \pm 0.8(5.0-7.6)$ & - & $6.4 \pm 0.9(5.0-7.8)$ & - & - & - & $4.9(4.1-6.2)$ & - \\
\hline
\end{tabular}

${ }^{\mathrm{z}}$ All measurements are in $\mu \mathrm{m}$ and in the form: mean \pm standard deviation (range), except the ratios and percentages. $n=$ number of measured specimens, $a=$ body length/greatest body diameter, $b=$ body length/distance from anterior end to posterior end of median pharyngeal bulb, $b^{\prime}=$ body length/distance from anterior end to posterior end of pharyngeal gland lobe, $c=$ body length/tail length, $c^{\prime}=$ tail length/body diameter at anus or cloaca, $L=$ overall body length, $O V=$ anterior genital tract length/body length $\%, V=$ distance of anterior body end from the vulva/body length $\%, \mathrm{VA}=$ vulva anus distance. 
(1972) for fixed specimens of $A$. besseyi; lateral field marked by four incisures; genital tracts with a conspicuous spermatheca packed with round sperm and a post uterine branch short and without sperm or with a few sperm in 5\% of examined specimens. Tail terminus with a mucro having three or four finely pointed processes as reported in the literature (Fig. 2). Only two male specimens were found in the population from photosynthetic leaves. These two specimens had a shorter body than that reported in the original description: 525.3 (499.2-551.4) $\mu \mathrm{m}$ versus 660-750 $\mu \mathrm{m}$. A wider range of body length (440-720 $\mu \mathrm{m})$ of $A$. besseyi males was reported by Allen (1952) for populations collected from Florida strawberry and Fortuner (1970) for a population from rice $(530-610 \mu \mathrm{m})$ or reared on the fungus Alternaria oleracea Milb. (440-590 $\mu \mathrm{m})$. Stylet and spicula were 12 and 17.5 to $18.8 \mu \mathrm{m}$ long, respectively, and in the range of the values $11.4(10-12.5) \mu \mathrm{m}$ and 19.2 (18-21) $\mu \mathrm{m}$, respectively, reported for these characters by Fortuner (1960). The population reared on M. fructicola contained males that had bodies 541 to $592 \mu \mathrm{m}$ long (Fig. 3). These values were smaller than those reported in the original description, but in the range of those reported for the populations measured by Allen (1952) and Fortuner (1960). Morphometrics of both populations from photosynthetic strawberry leaves and fungal cultures were not different and fit well those reported for $A$. besseyi both in the original description and later descriptions (Fortuner 1970; Franklin and Siddiqi 1972; Hunt 1993).

The results of the morphological study of the nematode population isolated from Florida senescent and desiccated strawberry leaves, cultured in $M$. fructicola, and tentatively identified by Oliveira et al. (2018) as 'A. fujianensis', indicated that the morphological and biological characteristics of this population did not match those reported in the description of this nematode species from China (Zhuo et al. 2010). The analyzed Florida population was without males, whereas the described type population of A. fujianensis is amphimictic (Zhuo et al. 2010). Some morphometrics of this population (Table 3 ) described in this study as A. pseudogoodeyi sp. n. overlap those reported in the original description of type $A$. fujianensis and, also, those of the characters published for 'A. fujianensis' populations without males from seeds of Brachiaria sp. (Brazil), Phaseolus vulgaris (Costa Rica), and Oryza sativa (Japan) and cultured on Fusarium solani (de Jesus et al. 2016). The different reproductive habits of females of Florida A. pseudogoodeyi sp. n. were reflected in morphological differences in their genital tract when compared with that of females from China. Females of the Florida population are different from those of the type species from China in that they lacked a functional and conspicuous spermatheca (Fig. 4). Characters that were shared between Florida females and those of the type population from China include a comparable stylet length (12.6 [12-13] $\mu \mathrm{m}$ vs 13 [12.5-14] $\mu \mathrm{m}$ ) and a stellate tail (Shahina 1996), having a terminal mucro consisting of a trunk bearing four short blunt processes (Fig. 4). However, females of A. pseudogoodeyi sp. n. from Florida have a short ovary not reaching the esophageal glands and oocytes disposed in several unaligned rows rather than long ovary reaching the esophageal glands and oocytes arranged in a single row as described for the type A. fujianensis. They have also a shorter postuterine branch $(38.3$ [32.6-47.5] $\mu \mathrm{m}$ vs. 86 [68-110] $\mu \mathrm{m})$ and smaller values of PSU/VA (\%) (21.9 [17.6-28.7] vs. 37.6 [32.1-44.4]). These differences in the reproductive habits and morphology of the genital tract of females of Florida A. pseudogoodeyi sp. n. compared with those of the type A. fujianensis from China indicate that these two aphelenchoidids are distinct species. The morphological characters of the populations without males of putative 'A. fujianensis' from Brazil, Costa Rica, and Japan matched those of the Florida population, but their morphometrics were highly variable (de Jesus et al. 2016) (Table 3). The results of extensive morphological comparisons between the Florida population and other

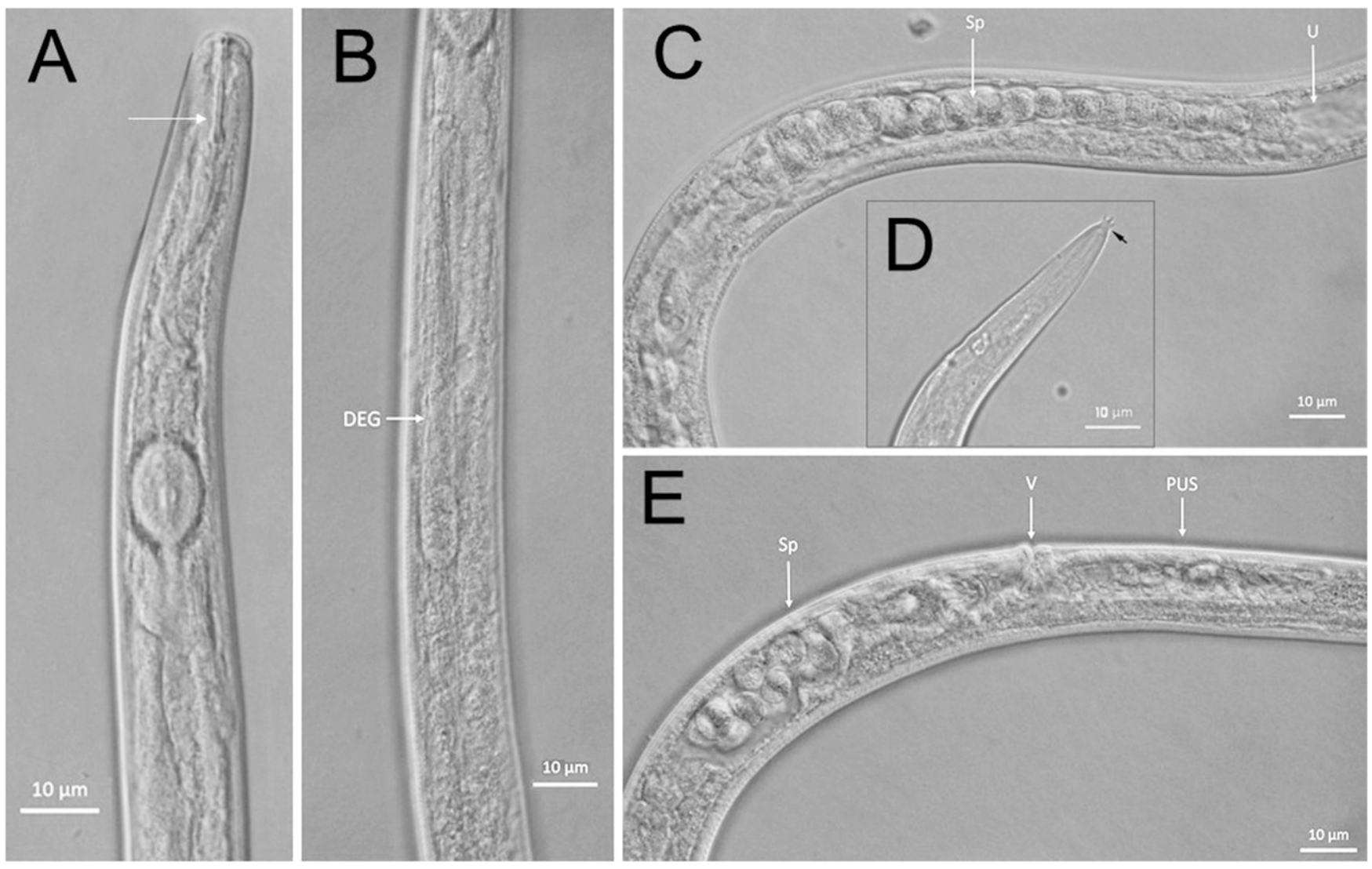

Fig. 2. Photomicrographs of Aphelenchoides besseyi female. A and B, Anterior portions of the body. Note, in A, the stylet (arrowed) and, in B, the dorsal esophageal gland (DEG) overlapping the intestine. C, Portion of the genital tract showing the long spermatheca filled with round sperm (Sp). Note the sperm packed in rectangular cases in the anterior portion of the spermatheca. D, Tail ending in a mucro with three pointed processes (arrow). E, Posterior portion of the genital tract showing an enlarged oval spermatheca (Sp) filled with round sperm, the vulva (V), and the postuterine sac (PUS) containing a few sperm. 
Aphelenchoides species with stellate tails (Shahina 1996; Hunt 2007) indicate that this species of Aphelenchoides from Florida is a new species described and named herein as Aphelenchoides pseudogoodeyi sp. n. because of the similarity with A. goodeyi, a species found in India (Siddiqi and Franklin 1967).

Aphelenchoides pseudogoodeyi (specific epithet derived from the Greek term $\Psi \varepsilon v \delta \eta \sigma=$ false and goodeyi portion of the scientific name of Aphelenchoides goodeyi.) sp. n. = A. fujianensis apud de Jesus et al. (2016).

Measurements and features of this new species are shown in Table 3 and Figures 4 to 6 of this article and Figure 2 in de Jesus et al. (2016).

Description. Female. Body tapering slightly anteriorly and more distinctly in the posterior portion, which is slightly curved in $60 \%$ of specimens and straight in $40 \%$ of them $(n=46)$. Body marked by faint annuli (1.0-1.3 $\mu \mathrm{m}$ thick). Lateral field 3-5 $\mu \mathrm{m}$ wide marked by four incisures or three bands. The inner lines are closely arranged and form a narrow central band. Head slightly offset. Stylet weak with distinct cone and knobs; conus occupying approximately 40.0 to $44.7 \%$ of its total length. Pharynx with the characteristic features of the genus. Procorpus cylindrical connected posteriorly with a prominent spheroid metacorpus, which has the sclerotized valve apparatus located in a central or post median position in 70 and $30 \%$ of the examined specimens $(n=20)$, respectively. Isthmus narrow, surrounded by nerve ring $75.3 \pm 3.2(70.0-83.2) \mu \mathrm{m}(n=16)$ from anterior end in fixed specimens. The pharyngeal glands form a distinct lobe that overlaps the intestine dorsally. Excretory pore located posteriorly or at level of the nerve ring in 86 and $14 \%$ of the examined specimens $(n=21)$, respectively. Hemizonid and hemizonion not seen. The genital tract is short, monodelphic, and prodelphic and does not reach the pharyngeal gland lobe. Ovary is connected to the oviduct, which is followed by a nonfunctional spermatheca, an indistinct quadricolumella, and a large uterus ending in the vagina. Oocytes arranged in several unaligned rows. Postuterine sac prominent in some specimens but collapsed in $>40 \%$ of the specimens examined. Vulval lips protruding slightly from the body surface. Tail ending in a mucro with three or four cusp-like blunt processes.

Male. Not found.

Type host and locality. The type population was collected from senescent strawberry (Fragaria $\times$ ananassa) leaves in Plant City, FL (latitude 27.994868, longitude 82.065017). The population was reared on the fungus Monilinia fructicola.

Type material. One holotype and paratypes mounted on glass slides deposited in the nematode collection of the National Museum of Natural Sciences, Madrid, Spain. Additional paratypes, six for each repository, sent to the U.S. Department of Agriculture Nematode Collection, Beltsville, MD; University of California Riverside Nematode Collection, Riverside, CA; WaNeCo, Plant Protection Service, Wageningen, The Netherlands; and Nematode Collection of FERA, Sand Hutton, UK.
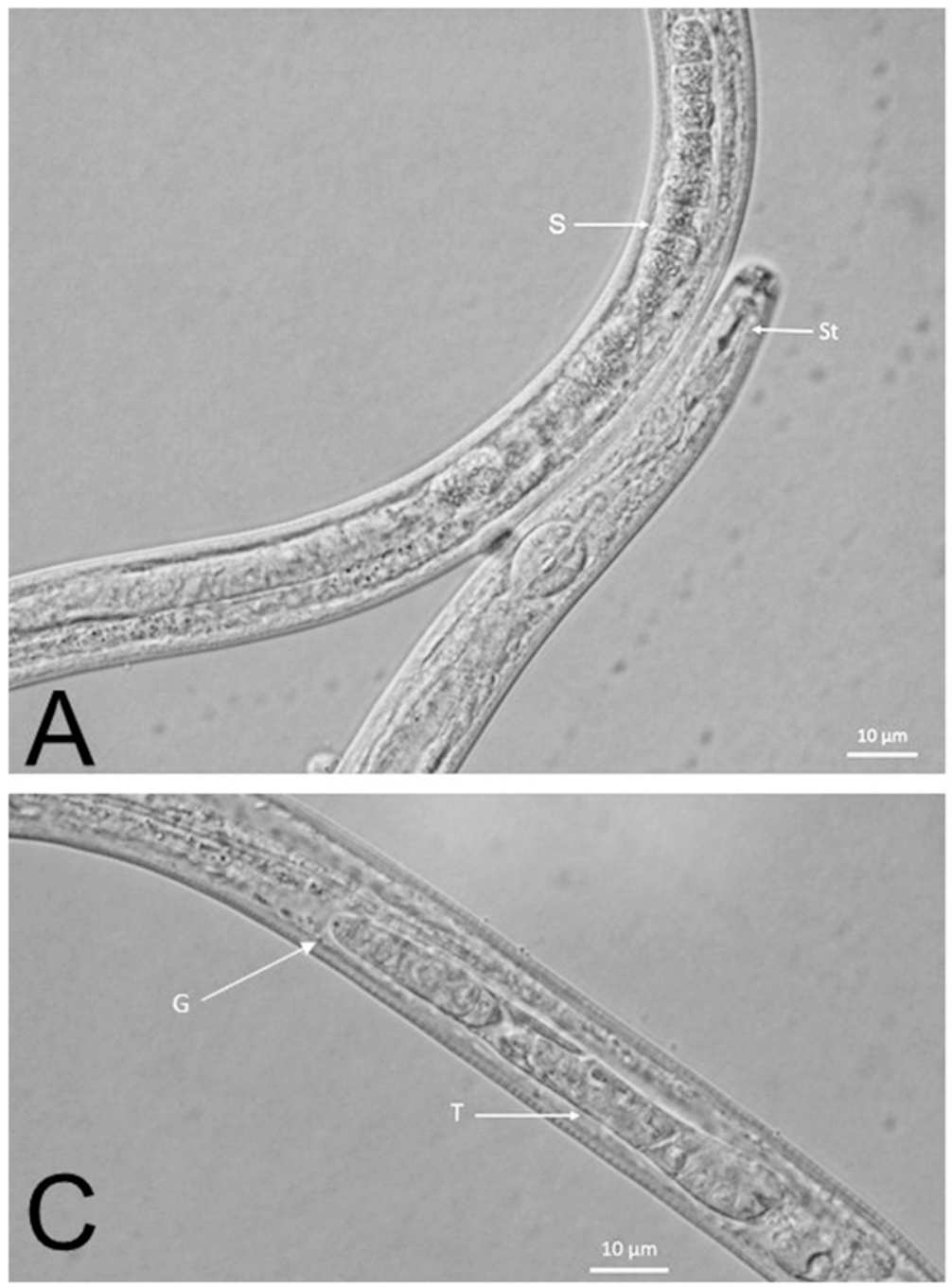

Fig. 3. Photomicrographs of Aphelenchoides besseyi male. A, Anterior and middle portions of the body showing the style (St) and the sperm (S) packed in rectangular cases in the testis (T). B, Lateral field (LF) marked by four incisures. C, Anterior portion of the testis showing the germinal zone (G) at the tip. D, Posterior portion of the body showing the spicules. Their dorsal limb (DL) is well defined. The condilus $(\mathrm{Cn})$ and rostrum (Rs) are not well developed.
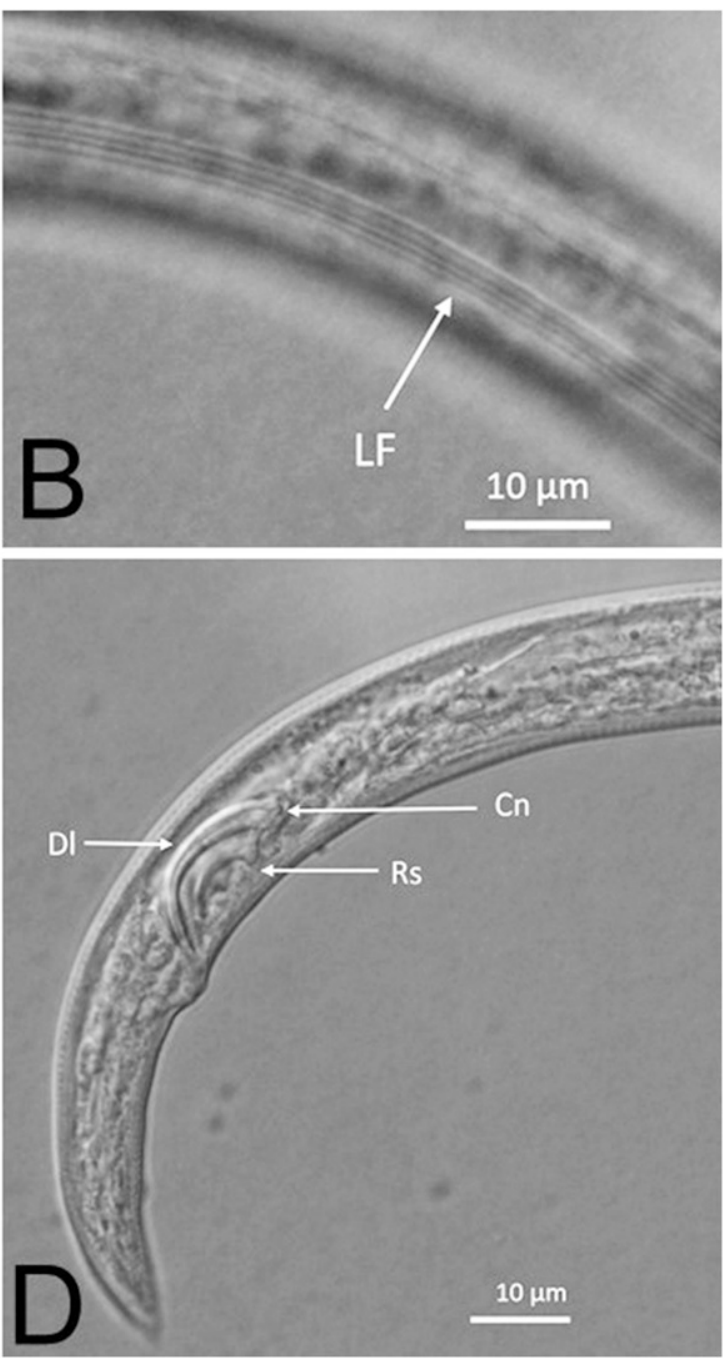
Diagnosis and relationship. A. pseudogoodeyi sp. n. is characterized biologically by absence of males and morphologically by females having a wide body (18.0-26.7 $\mu \mathrm{m})$, slightly curved posteriorly; a genital tract with short ovary not reaching the esophageal gland lobe, and containing oocytes arranged in multiple unaligned rows; a nonfunctional spermatheca; a post uterine branch often indistinct and occupying, when visible, 17.2 to $18.7 \%$ of vulva anus distance; and a tail ending in a stellate mucro consisting of a peg with three to four blunt processes. Selected differential characters that separate A. pseudogoodeyi sp. n. from the 28 stellate-tailed Aphelenchoides species described so far and belonging to the Group 3 of Aphelenchoides with stellate tail (Shahina 1996) are listed in

Table 3. Morphometrics of the holotype, live, and fixed females of Aphelenchoides pseudogoodeyi sp. $\mathrm{n}$. from strawberry and reared on fungi in Florida and other 16 conspecific populations from Brazil (13), Costa Rica (1), and Japan (2) (de Jesus et al. 2016) compared with those of Aphelenchoides fujianensis and Aphelenchoides goodeyi

\begin{tabular}{|c|c|c|c|c|c|c|}
\hline \multirow[b]{2}{*}{ Character $^{w}$} & \multicolumn{4}{|c|}{ Aphelenchoides pseudogoodeyi sp. n. } & \multirow[b]{2}{*}{$\begin{array}{l}\text { Type A. fujianensis } \\
\text { from China } \\
\text { (Zhuo et al. } \\
\text { 2010) } \\
\end{array}$} & \multirow[b]{2}{*}{ 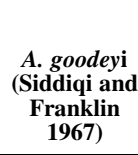 } \\
\hline & Holotype & Live (N18-01001-3) & $\begin{array}{l}\text { Paratypes fixed } \\
\text { (N18-01001-3) }\end{array}$ & $\begin{array}{c}\text { Conspecific populations } \\
\text { identified as } \\
\text { 'A. fujianensis’ by } \\
\text { de Jesus et al. (2016) }\end{array}$ & & \\
\hline$n$ & - & 10 & 16 & 300 & 20 & 20 \\
\hline$L$ & 725 & $821.8 \pm 61.0(698.8-893.9)$ & $721.2 \pm 33.0(663.8-776.0)$ & 603-868 (474-992) & $866 \pm 45(803-941)$ & $(460-610)^{\mathrm{x}}$ \\
\hline$a$ & 34.1 & $34.3 \pm 2.4(30.0-38.0)$ & $33.9 \pm 2.2(29.1-37.8)$ & $30.5-38.4(23.7-42.3)$ & $35.2 \pm 1.4(31.5-36.3)$ & $(29-39)$ \\
\hline$b$ & 10.2 & $10.4 \pm 0.8(8.5-11.5)$ & $10.3 \pm 0.3(9.6-10.8)$ & - & $10.6 \pm 0.7(9.8-13.0)$ & $(8-10)$ \\
\hline$b^{\prime}$ & 5 & $4.9 \pm 0.3(4.2-5.2)$ & $5.0 \pm 0.2(4.5-5.3)$ & - & - & - \\
\hline$c$ & 17.4 & $17.4 \pm 0.7(16.1-19.0)$ & $17.2 \pm 0.9(15.3-18.6)$ & $15.5-19.2(11.0-21.8)$ & $16.9 \pm 0.9(15.1-18.2)$ & $(14-18)$ \\
\hline$c^{\prime}$ & 3.2 & $3.4 \pm 0.2(3.0-3.8)$ & $3.4 \pm 0.3(3.1-4.2)$ & $2.9-3.7(1.9-4.3)$ & $4.0 \pm 0.3(3.5-4.4)$ & $3.7(n=1)$ \\
\hline Max. body diameter & 21.2 & $24.1 \pm 2.4(19.3-27.2)$ & $21.4 \pm 2.1(18.0-26.7)$ & $19.1-24.9(14.4-27.7)$ & $25.0 \pm 1.5(23-28)$ & $(14-19)^{\mathrm{y}}$ \\
\hline $\begin{array}{l}\text { Body diameter at } \\
\text { anus distance }\end{array}$ & 12.8 & $14 \pm 1.0(11.4-15.3)$ & $12.2 \pm 0.6(10.4-12.9)$ & $10.9-15.0(10.0-17.8)$ & - & $9.5^{\mathrm{x}}$ \\
\hline$V$ & 69 & $69.6 \pm 0.7(68.1-70.8)$ & $69.7 \pm 0.8(68.5-71.6)$ & $68.1-71(62.1-75.0)$ & $68 \pm 0.9(67-69)$ & $(69-72)$ \\
\hline$O V$ & 24.6 & $25.3 \pm 3.5(17.9-32.1)$ & $24.3 \pm 1.7(22-28)$ & - & - & - \\
\hline $\begin{array}{l}\text { Anterior genital } \\
\text { tract length }\end{array}$ & 179 & $208.6 \pm 36.0(124.9-267.3)$ & $175.2 \pm 10.7(151.5-192.0)$ & - & - & 156 \\
\hline Lip region width & 7.3 & $7.9 \pm 0.2(7.5-8.2)$ & $7.1 \pm 0.2(7.0-7.5)$ & $6.9-8.0(6.3-9.0)$ & $7.0 \pm 0.6(6.0-7.5)$ & (7) $(n=1)$ \\
\hline Lip region height & 3 & $3.2 \pm 0.2(3.0-3.7)$ & $3.0 \pm 0.1(2.8-3.1)$ & $3.0-3.2(2.5-4.0)$ & $2.5 \pm 0.2(2-3)$ & 3 \\
\hline Stylet length & 12.1 & $12.6 \pm 0.4(12-13)$ & $12.2 \pm 0.2(12.0-12.7)$ & $12.3-12.8(10.9-13.5)$ & $13.0 \pm 0.3(12.5-14.0)$ & $(11.5-12.5)$ \\
\hline Stylet cone length & 5.1 & $5.2 \pm 0.3(4.9-5.8)$ & $5.1 \pm 0.2(5.0-5.8)$ & - & - & - \\
\hline Stylet knob height & 1.5 & $1.6 \pm 0.2(1.2-2.0)$ & $1.5 \pm 0.2(1.2-1.8)$ & - & - & - \\
\hline Stylet knob width & 2.9 & $2.5 \pm 0.4(2.1-3.0)$ & $2.2 \pm 0.2(2.0-2.8)$ & - & - & - \\
\hline Metacorpus length & 18 & $18.6 \pm 0.7(18.0-19.8)$ & $17.6 \pm 0.4(17.0-18.3)$ & $17.2-19.6(15.0-21.0)$ & $17.5 \pm 1.1(16.0-20)$ & $15^{\mathrm{y}}$ \\
\hline Metacorpus width & 12.8 & $13.9 \pm 0.8(12-15)$ & $12.3 \pm 0.7(10.8-13.4)$ & $12.4-15.1(10.0-19.0)$ & $14 \pm 1.0(12.5-16)$ & $9.5^{\mathrm{y}}$ \\
\hline $\begin{array}{l}\text { Metacorpus } \\
\text { valve length }\end{array}$ & 5.4 & $5.4 \pm 0.4(5.0-5.9)$ & $5.3 \pm 0.4(4.9-6.0)$ & - & - & - \\
\hline $\begin{array}{l}\text { Metacorpus } \\
\text { valve width }\end{array}$ & 4.1 & $4.0 \pm 0.2(3.6-4.4)$ & $3.9 \pm 0.2(3.3-4.2)$ & - & - & - \\
\hline Pharynx length & 71 & $79.1 \pm 3.3(73.2-84.1)$ & $69.9 \pm 2.6(64-74)$ & - & $73 \pm 2.7(64-75)$ & - \\
\hline $\begin{array}{l}\text { Pharyngeal } \\
\text { overlap length }\end{array}$ & 73.3 & $88.6 \pm 7.8(80.2-107.9)$ & $74.8 \pm 3.8(67-80)$ & - & - & - \\
\hline $\begin{array}{l}\text { Ant. end to } \\
\text { pharyngeal } \\
\text { gland lobe } \\
\text { distance }\end{array}$ & 144.3 & $167.7 \pm 8.9(155.4-185.1)$ & $144.7 \pm 5.5(131.0-152.3)$ & - & - & - \\
\hline $\begin{array}{l}\text { Anterior end to } \\
\text { excretory } \\
\text { pore distance }\end{array}$ & 81.2 & $94.7 \pm 7.4(85.6-108.9)$ & $79.4 \pm 3.1(75.0-86.1)$ & - & - & 76 \\
\hline $\begin{array}{l}\text { Post uterine sac } \\
\text { (PUS) length }\end{array}$ & 33.6 & $44.9 \pm 13.4(28.7-74.2)$ & $38.3 \pm 3.8(32.6-47.5)$ & $42.7-58.4(28.1-72.0)$ & $86.0 \pm 11.4(68-110)^{\mathrm{z}}$ & 47 \\
\hline $\begin{array}{l}\text { Vulva anus } \\
\text { distance (VA) }\end{array}$ & 184.1 & $202.3 \pm 17.1(165.3-219.0)$ & $175.5 \pm 7.4(165.3-187.0)$ & - & $229.0 \pm 15.4(205-250)$ & $115^{\mathrm{y}}$ \\
\hline $\begin{array}{l}\text { Ant. end to } \\
\quad \text { vulva distance }\end{array}$ & 499.4 & $572.2 \pm 43.0(490.0-625.7)$ & $502.5 \pm 26.3(455.0-544.5)$ & - & - & $362^{y}$ \\
\hline $\begin{array}{l}\text { Post end to } \\
\text { vulva distance }\end{array}$ & 225.6 & $249.6 \pm 19.4(208.8-269.2)$ & $218.9 \pm 8.6(206.8-233.5)$ & - & - & $148^{y}$ \\
\hline Tail length & 41.5 & $47.3 \pm 2.8(43.5-51.4)$ & $42.0 \pm 1.4(40.0-44.5)$ & $36.1-50.7(26.9-54.2)$ & $51.0 \pm 3.0(46-58)$ & $34^{y}$ \\
\hline $\begin{array}{l}\text { Body width at } \\
\text { vulva }(B W V)\end{array}$ & 18.8 & $22.7 \pm 2.1(18.8-25.7)$ & $19.4 \pm 1.1(17.8-21.8)$ & - & - & $15^{\mathrm{y}}$ \\
\hline$P U S / B W V$ & 1.8 & $1.9 \pm 0.5(1.3-3)$ & $2 \pm 0.2(1.6-2.5)$ & - & - & $3.1^{\mathrm{y}}$ \\
\hline Mucro length & 2.7 & $2.5 \pm 0.4(2-3)$ & $2.9 \pm 0.4(2.1-3.8)$ & - & - & - \\
\hline$P U S / L \%$ & 4.6 & $5.4 \pm 1.5(3.4-8.3)$ & $5.3 \pm 0.6(4.3-7.1)$ & - & - & $9.2^{\mathrm{y}}$ \\
\hline PUS/VA \% & 18.3 & $22.3 \pm 6.4(13.1-34.1)$ & $21.9 \pm 2.6(17.6-28.7)$ & $31.0-36.3(16.3-44.9)$ & $37.6 \pm 4.5(32.1-44.4)^{\mathrm{z}}$ & $39.8^{\mathrm{y}}$ \\
\hline Lateral field width & 4.1 & $4.8 \pm 0.3(4-5)$ & $4.1 \pm 0.4(3.2-5.0)$ & - & - & $3^{y}$ \\
\hline
\end{tabular}

${ }^{\mathrm{w}}$ All measurements are in $\mu \mathrm{m}$ and in the form: mean \pm standard deviation (range), except the ratios and percentages. $n=$ number of measured specimens, $a=$ body length/greatest body diameter, $b=$ body length/distance from anterior end to posterior end of median pharyngeal bulb, $b^{\prime}=$ body length/ distance from anterior end to posterior end of pharyngeal gland lobe, $c=$ body length/tail length, $c^{\prime}=$ tail length/ body diameter at anus or cloaca, $L=$ overall body length, $O V=$ anterior genital tract length/body length $\%, V=$ distance of anterior body end from the vulva/body length $\%$.

${ }^{x}$ Smallest and greatest average values of 16 populations. Values in parentheses are minimum and maximum values across the 16 populations.

y Characters of A. goodeyi differing from those of A. pseudogoodeyi sp. $\mathrm{n}$.

${ }^{\mathrm{z}}$ Characters of A. fujianensis differing from those of A. pseudogoodeyi $\mathrm{sp} . \mathrm{n}$. 


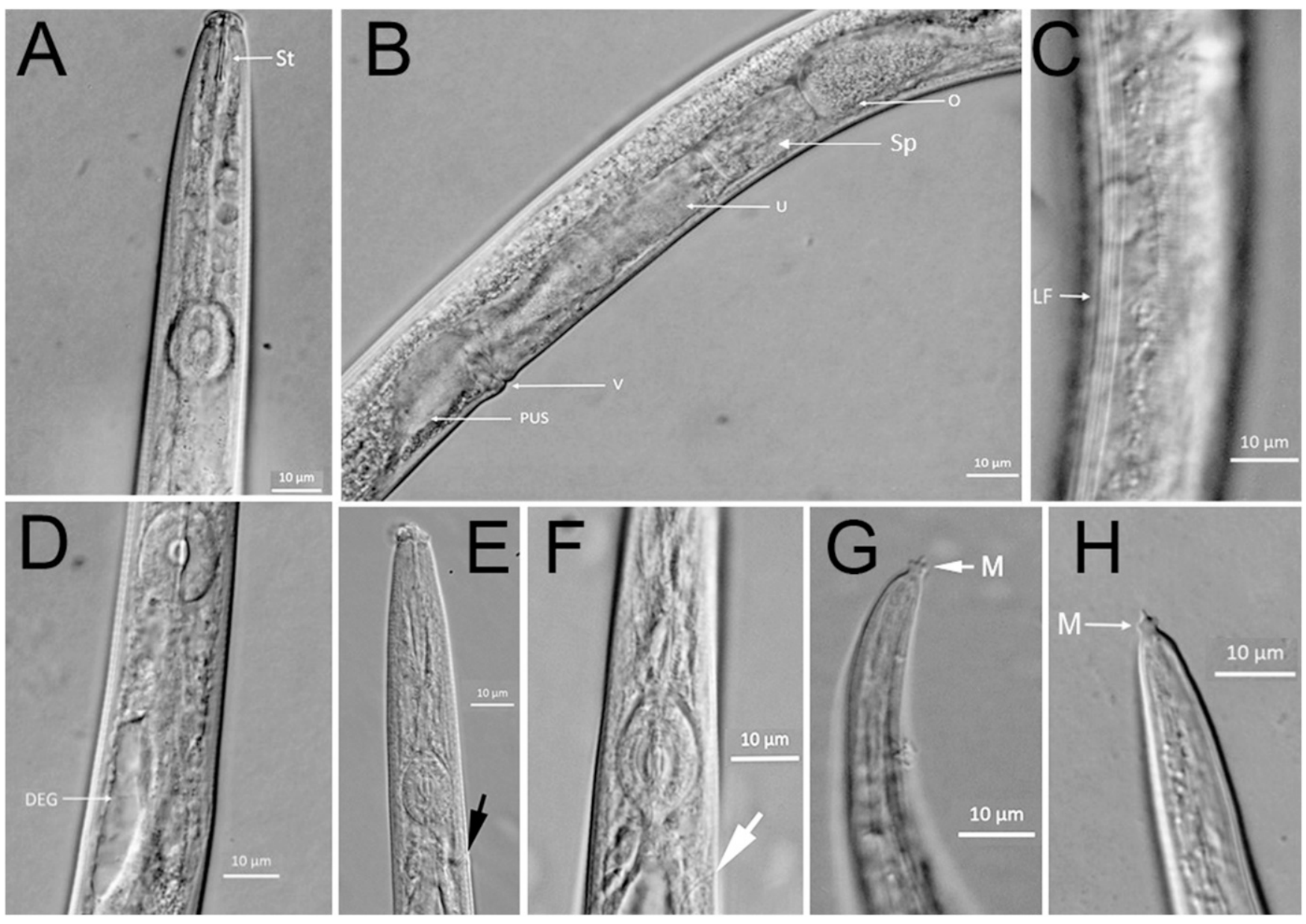

Fig. 4. Photomicrographs of Aphelenchoides pseudogoodeyi sp. n. (female). A, Anterior portion of the body showing the stylet (St). B, Posterior portion of the genital tract with a large oocyte $(\mathrm{O})$ adjacent to a nonfunctional and rectangular spermatheca (Sp). Note the large uterus (U), the vulva (V) and the saccate postuterine branch (PUS). C, Lateral field (LF) marked by four incisures. $D$ to F, Anterior portion of the body showing the pharyngeal region. Note the dorsal esophageal gland lobe (DEG) in $\mathbf{D}$ and the excretory duct and pore (arrow) in $\mathbf{E}$ and $\mathbf{F}$. $\mathbf{G}$ and $\mathbf{H}$, Posterior end showing shape variations of the mucro (M) with blunt and short processes.

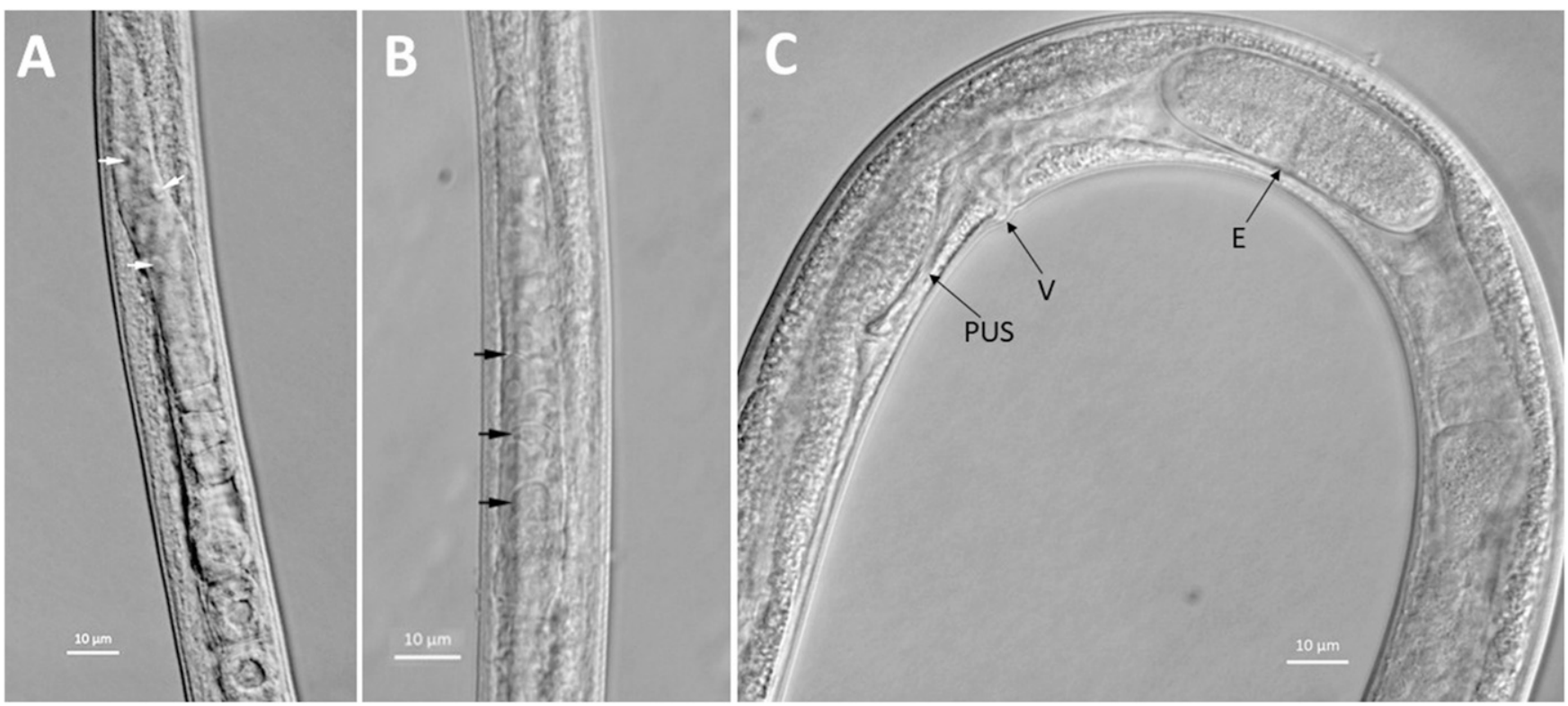

Fig. 5. Photomicrographs of a female of Aphelenchoides pseudogoodeyi sp. n. A and B, Ovaries showing oocytes arrowed arranged in multiple unaligned rows. C, Posterior portion of the genital tract showing an egg (E) in the uterus and a collapsed postuterine sac (PUS). V = vulva. 


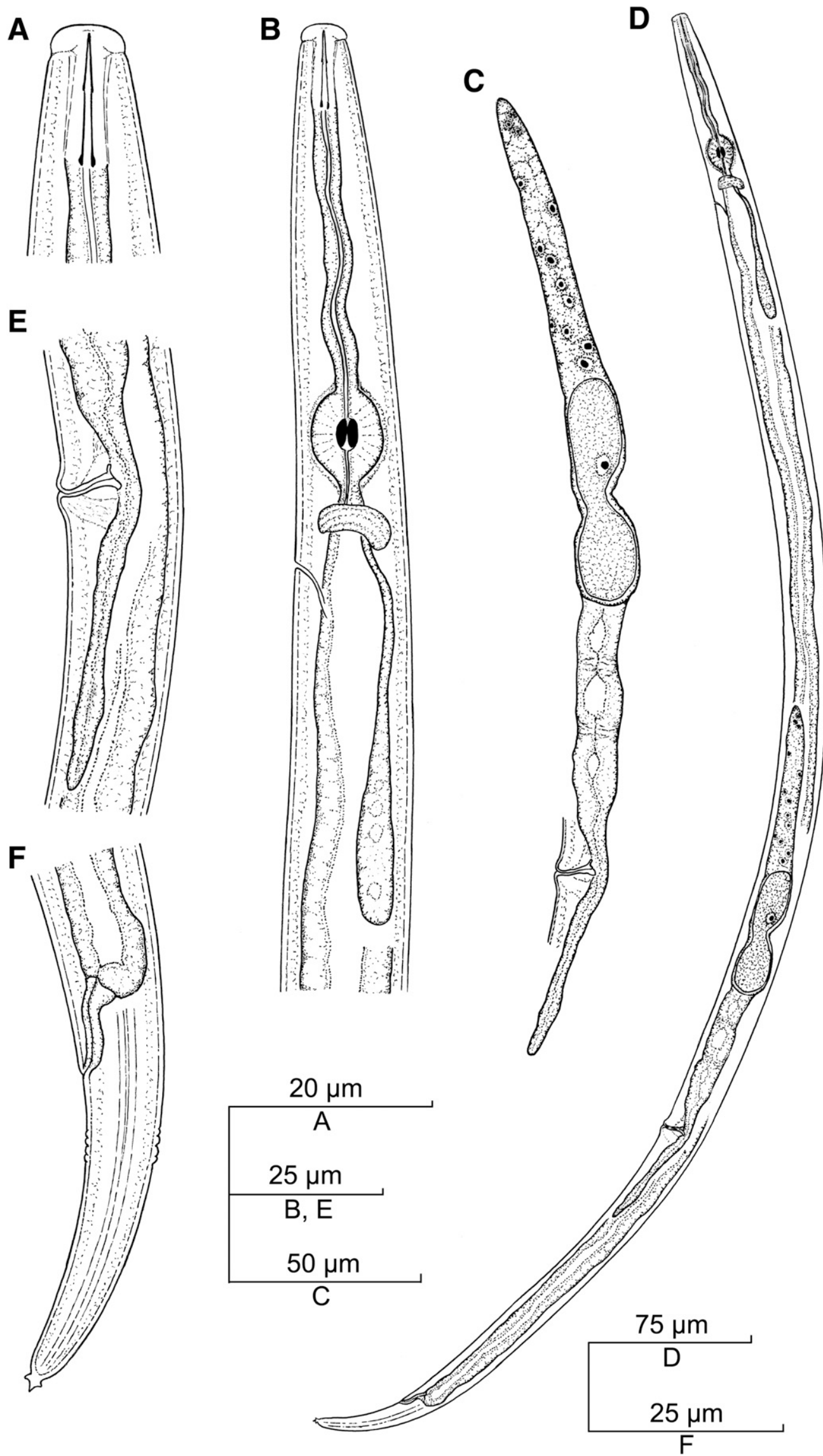

Fig. 6. Camera lucida line drawings of a female of Aphelenchoides pseudogoodeyi sp. n. from strawberry in Florida. A, Anterior portion of the body showing the stylet. B, Pharyngeal region. C, Genital tract. D, Entire body. E, Vulvar region. F, Posterior portion of the body. 
Table 4. This new species differs from 17 of these stellate-tailed Aphelenchoides by the absence of males. Selected differential characters between $A$. pseudogoodeyi sp. n. and A. besseyi are added because these two species occur together on strawberry and include a greater body width $(24.11 \pm 2.4$ [19.3 to 27.2$] \mu \mathrm{m}$ vs. $15.7 \pm 1.3$ [13.3 to 17.8$] \mu \mathrm{m}$ ) and the shape of the tail's mucro that has shorter processes in A. pseudogoodeyi than in A. besseyi $(<1 \mu \mathrm{m}$ long versus $>1 \mu \mathrm{m}$ long). A. pseudogoodeyi sp. n. differs from six of the stellatetailed Aphelenchoides without males by having a lateral field marked by four lines rather than two or three. The remaining morphologically related five species without males and having lateral fields with four lateral lines include A. asteromucronatus Eroshenko, 1967, A. goodeyi Siddiqi and Franklin, 1967, A. hylurgi (original U.S. population) Massey, 1974, A. jonesi Singh, 1977, A seiachus Nesterov, 1973, and A. silvester Andrássy, 1968. A. pseudogoodeyi sp. n. differs from $A$. asteromucronatus in having a longer stylet and body (12 to 12.7 vs. $9 \mu \mathrm{m}$ and 663.8-776 vs. 390 to $530 \mu \mathrm{m}$, respectively) and ratio c value (15.3 to 18.6 vs. 10.9 to 14.5 ); from $A$. goodeyi in having longer body and vulva anus distance (663.8 to $776 \mathrm{vs.}$ 460 to $610 \mu \mathrm{m}$ and 165.3 to 187 vs. $115 \mu \mathrm{m}$, respectively), longer and larger metacorpus (17.0 to 18.3 and 10.8 to 13.4 vs. 15 and $9.5 \mu \mathrm{m}$, respectively) and larger lateral field (3.2 to $5.0 \mathrm{vs}$. $3.0 \mu \mathrm{m}$ ); from the original U.S. population of A. hylurgi in having longer body (663.8 to 776.0 vs. $570.0 \mu \mathrm{m})$; larger a ratio $(29.1$ to 37.8 vs. 26.6); shorter stylet (12.0 to 12.7 vs. $13.0 \mu \mathrm{m}$ ); more posterior vulva position ( 66.5 to 71.6 vs. 66.0 ), shorter ovary not reaching the nerve ring rather than extending to nerve ring like in A. hylurgi; from A. jonesi in having shorter body (663.8 to 776.0 vs. 720.0 to $990.0 \mu \mathrm{m})$; larger a ratio (29.1 to 37.8 vs. 20.0 to 28.0 ); and shorter post uterine sac ( 32.6 to 47.5 vs. 60.0 to $70.0 \mu \mathrm{m}$ ) and comparatively longer tail ( $c^{\prime}=3.1$ to 4.2 vs. 1.7 to 2.4 ); from $A$. seiachicus in having a longer body (663.8 to 776.0 vs. $374.0-420.0 \mu \mathrm{m})$; longer stylet (12.0 to 12.7 vs. $9.5 \mu \mathrm{m})$; longer tail ( 40.0 to 44.5 versus $30.0 \mu \mathrm{m}$ ), and greater c values (15.3 to 18.6 vs. 12.1 to 14.5 ); and finally from $A$. silvester in having longer body (663.8 to 776.0 vs. 480.0 to $560.0 \mu \mathrm{m})$ and longer stylet $(12.0$ to 12.7 vs. 9.5 to $10.0 \mu \mathrm{m})$.

Molecular characterization and phylogenetic relationships within Aphelenchoides species with stellate tails. Phylogenetic relationships among Aphelenchoides species were inferred from the analyses of 18S rRNA, 28S rRNA, and partial COI gene sequence datasets.

$18 S$ rRNA gene. The 18S rRNA gene alignment was 1579 base pairs (bp) in length and consisted of 50 sequences of species and populations of Aphelenchoides and Robustodorus subtenuis used as an outgroup taxon. The BI consensus tree (Fig. 7) revealed the following: (i) two highly supported sister clades containing populations of $A$. besseyi and A. ritzemabosi; (ii) the clade containing $A$. pseudogoodeyi sp. n., A. fujianensis, and Aphelenchoides medicagus from alfalfa, USA; and (iii) the clade with two unidentified Aphelenchoides sp. from wood packing materials. The clade with A. besseyi populations is divided into three subclades containing populations from different hosts: (i) rice, (ii) fern and leguminous plants, and (iii) strawberry, with the $A$. besseyi population from Florida. The largest clade with A. pseudogoodeyi sp. n. in the tree

Table 4. Selected morphological and biological discriminatory characters used to differentiate Aphelenchoides pseudogoodeyi sp. n. from the known 28 species with stellate tails forming the Group 3 (Shahina 1996) in the genus Aphelenchoides ${ }^{\mathrm{x}}$

\begin{tabular}{|c|c|c|c|c|c|c|c|c|}
\hline Species of Aphelenchoides & $L(\mu \mathrm{m})^{\mathbf{y}}$ & $a^{\mathbf{y}}$ & $c^{\mathbf{y}}$ & $c^{, y}$ & $\begin{array}{l}\text { Stylet length } \\
(\mu \mathrm{m})\end{array}$ & $\begin{array}{l}\text { Tail length } \\
\qquad(\mu \mathrm{m})\end{array}$ & $\begin{array}{l}\text { Lateral } \\
\text { lines }\end{array}$ & Males \\
\hline A. pseudogoodeyi sp. $\mathrm{n}$. & $664-776$ & $29.1-37.8$ & $15.3-18.6$ & $3.1-4.2$ & $12-12.7$ & $40-44.5$ & 4 & Absent \\
\hline A. aligarhiensis Siddiqi et al. 1967 & $500-700$ & $23-35$ & $13-32$ & 3.2 & 10 & 33.3 & 4 & Present \\
\hline A. andrassyi Husain and Khan 1967 & $390-440$ & 23-28 & 6-12 & - & 9-10 & 60 & 3 & Absent \\
\hline A. appendurus Singh 1967 & $720-880$ & $30.9-41.7$ & $14.3-20.2$ & 3 & 16.5-17 & 38.4 & 2 & Present \\
\hline A. asterocaudatus Das 1960 & 620 & 24.6 & 16 & 3 & 12 & 42 & 2 & Absent \\
\hline A. asteromисronatus Eroshenko 1967 & $390-530$ & $32-39$ & $10.9-14.5$ & 3.8 & 9 & - & 4 & Absent \\
\hline A. besseyi Florida, this study & $517-811$ & $34-49.7$ & $14.8-19.1$ & $3.6-4.7$ & $10-12.5$ & $33.6-46.5$ & 4 & Present \\
\hline A. brevistylus Jain and Sing 1984 & $390-630$ & $29.4-35$ & 11.1-15.7 & $3.6-5$ & 6-8 & $27-43$ & 2 & Absent \\
\hline A. fujianensis Zhuo et al. 2010 & 800-940 & $31.5-36.3$ & $15.1-18.2$ & $3.5-4.4$ & $12.5-14$ & $46-58$ & 4 & Present \\
\hline A. goldeni Suryawanshi 1971 & $430-470$ & 24-27 & $6-6.2$ & 7 & & 74 & 2 & Absent \\
\hline A. gorganensis Miraeiz et al. 2017 & $614-766$ & $28-36$ & $16.5-21$ & $2.6-3.4$ & $10-12$ & 31-41 & 4 & Present \\
\hline A. goodeyi Siddiqi and Franklin 1967 & $460-610$ & $29-39$ & $14-18$ & 3.7 & $11.5-12$ & 32.39 & 4 & Absent \\
\hline $\begin{array}{l}\text { A. hylurgi Massey } 1974 \text { (original } \\
\text { USA, population) }\end{array}$ & 570 & 26.6 & 14.7 & - & 13 & - & - & Absent \\
\hline $\begin{array}{l}\text { A. hylurgi (Australia, population } \\
\text { Bird et al. 1989) }\end{array}$ & $430-622$ & $22-35.1$ & $14-22$ & $2.6-3.9$ & $10-13$ & $26-38$ & 4 & Present \\
\hline A. jonesi Singh 1977 & $720-990$ & 20-28 & $16-22$ & $1.7-2.4$ & $11-14$ & $42-50$ & 4 & Absent \\
\hline $\begin{array}{l}\text { A. lychenicola Siddiqi and } \\
\text { Hawksworth } 1982\end{array}$ & $530-690$ & $32-43$ & $15-17$ & $3.2-3.9$ & $9.5-10$ & $34.2-41.7$ & 4 & Present \\
\hline A. medicagus Wang et al. 2019 & $518-709$ & $27.2-33.7$ & $16.4-19.9$ & $2.5-3.0$ & $9.1-12$ & 33-38 & 4 & Present \\
\hline A. menthae Lisetskaya 1971 & $690-980$ & $55-75$ & $15-19$ & 4.8 & 12.2 & 51.5 & 2 & Present \\
\hline A. nonveilleri Andrássy 1959 & 597 & 31 & 17 & 3 & 12.8 & - & 3 & Absent \\
\hline A. panaxifolia Liu et al. 1999 & $600-700$ & $39-50.8$ & $14.8-17.8$ & $3.9-5.3$ & 7.5-10 & 41.3 & 4 & Present \\
\hline A. primadentus Mobasseri et al. 2018 & $502-613$ & $27.1-36.9$ & $14.3-18.8$ & $2.5-3.8$ & $11.1-13.8$ & 29-38 & 3 & Present \\
\hline $\begin{array}{l}\text { A. ritzemabosi (Schwartz 1911) } \\
\text { Steiner and Buhrer } 1932\end{array}$ & $770-1240$ & $34-54$ & $15-23$ & 4 & 12 & - & 4 & Present \\
\hline A. seiachicus Nesterov 1973 & $374-420$ & $28.8-32.5$ & $12.1-14.5$ & 3 & 9.5 & 30 & - & Absent \\
\hline A. siddiqii Fortuner 1970 & $370-700$ & $26.7-38.9$ & $14.1-19.6$ & 2.6 & $11-12.5$ & 26 & 4 & Present \\
\hline A. silvester Andrássy 1968 & $480-560$ & 37-38 & $15-16$ & 4 & 9.5-10 & - & 4 & Absent \\
\hline A. stellatus Fang et al. 2014 & $547-699$ & $39.9-44.8$ & $14-20.9$ & $3.2-4.5$ & $12.3-17.5$ & - & 4 & Present \\
\hline A. tabarastanensis Golhasan et al. 2019 & $580-786$ & $29-35.7$ & $18.5-24.2$ & $2.3-2.9$ & 10-11 & 30-38 & 4 & Present \\
\hline A. unisexus Jain and Singh 1984 & $480-760$ & $30-36.9$ & $13-17.5$ & $3-3.8$ & 10-11 & $32-45$ & 2 & Absent \\
\hline A. wallacei Singh 1977 & $690-730$ & $22-23$ & $15-17$ & $2-2.5$ & 13.5-14 & $42-46$ & 4 & Present \\
\hline
\end{tabular}

${ }^{\mathrm{x}}$ Characters that differentiate each species from A. pseudogoodeyi sp. $\mathrm{n}$. are in bold.

y $a=$ body length/greatest body diameter, $c=$ body length/tail length, $c^{\prime}=$ tail length/ body diameter at anus or cloaca, $L=$ overall body length.

${ }^{\mathrm{z}}$ The U.S. and Australian populations of $A$. hylurgi are considered two different taxa until DNA sequences for these populations will be available to confirm that they are conspecific. 
contains 17 sequences of populations previously identified as $A$. besseyi, A. fujianensis, or Aphelenchoides sp., and the newly obtained sequence of the Florida population of A. pseudogoodeyi sp. n., from strawberry. All populations in this group are clearly separated from the type population of A. fujianensis collected originally from Pinus massoniana in China. Intraspecific $18 \mathrm{~S}$ rRNA gene variation within $A$. pseudogoodeyi sp. n. was from 0 to $0.5 \%$ and interspecific variation between $A$. pseudogoodeyi sp. n. and $A$. fujianensis ranged from 1.2 to $1.5 \%$. Intraspecific variation for the $A$. besseyi clade was 0 to $1.6 \%$.
$28 S$ rRNA gene. The $28 \mathrm{~S}$ rRNA gene alignment was $654 \mathrm{bp}$ in length and consisted of 97 sequences of Aphelenchoides and Robustodorus subtenuis used as an outgroup taxon. The BI tree (Fig. 8) revealed several clades: (i) A. besseyi, (ii) A. ritzemabosi and A. gorganensis; (iii) A. pseudogoodeyi sp. n., A. medicagus from alfalfa, USA, and Aphelenchoides sp. from pine wood packaging material; (iv) two Aphelenchoides species from Iran; and (v) A. fragariae and A. varicaudatus. Although relationships with populations of $A$. besseyi were not well resolved, A. besseyi parasitizing Fabaceae plants formed a separate subclade. Intraspecific partial 28S RNA

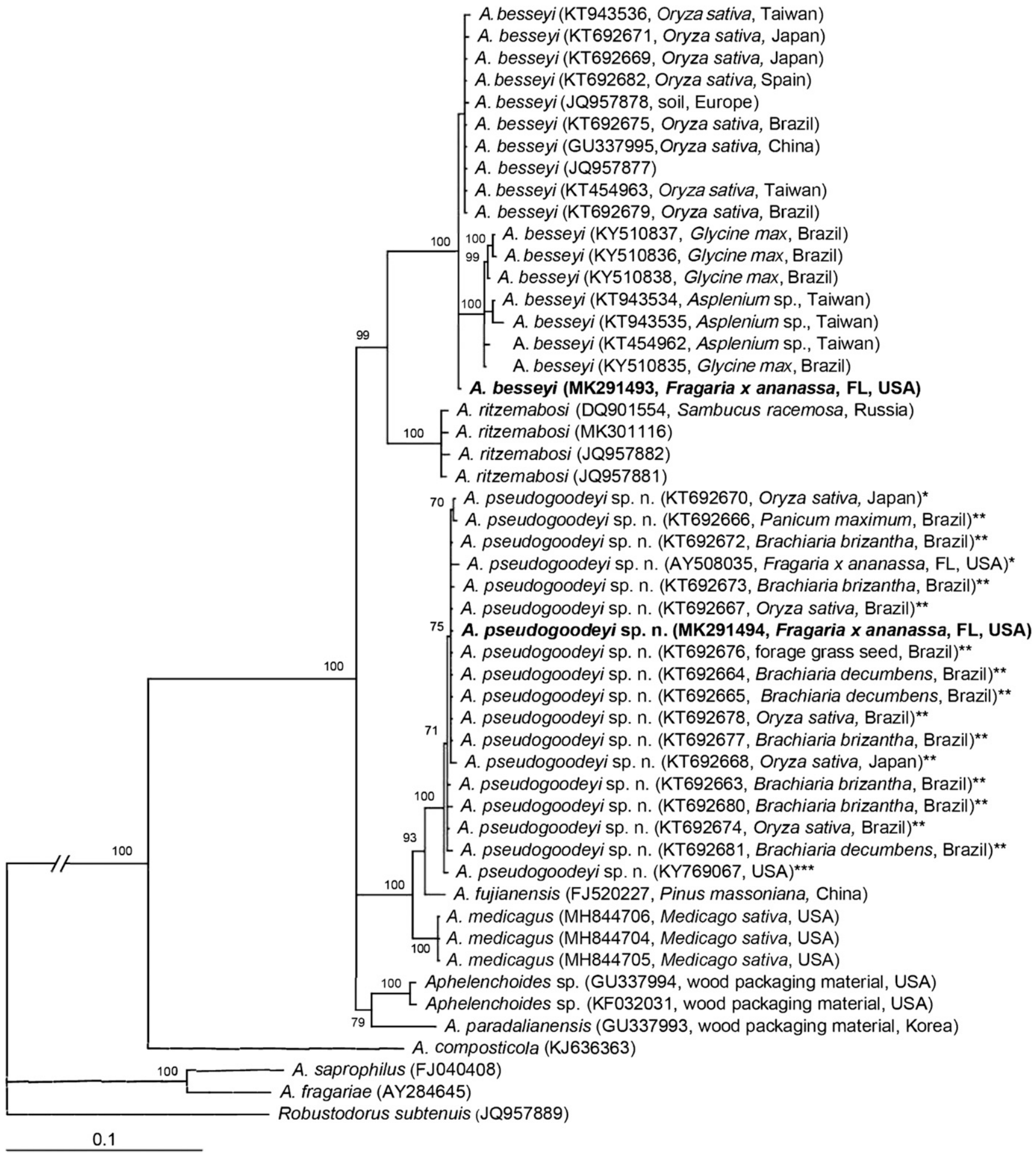

Fig. 7. Phylogenetic relationships within populations and species of the genus Aphelenchoides with stellate tails as inferred from Bayesian analysis using the $18 \mathrm{~S}$ rRNA gene sequence dataset with the GTR $+I+G$ model. Posterior probability more than $70 \%$ is given for appropriate clades. Newly obtained sequences are indicated in bold. Identified in the GenBank as *Aphelenchoides besseyi; ${ }^{* \star}$ Aphelenchoides fujianensis; ${ }^{* * *}$ Aphelenchoides sp. 


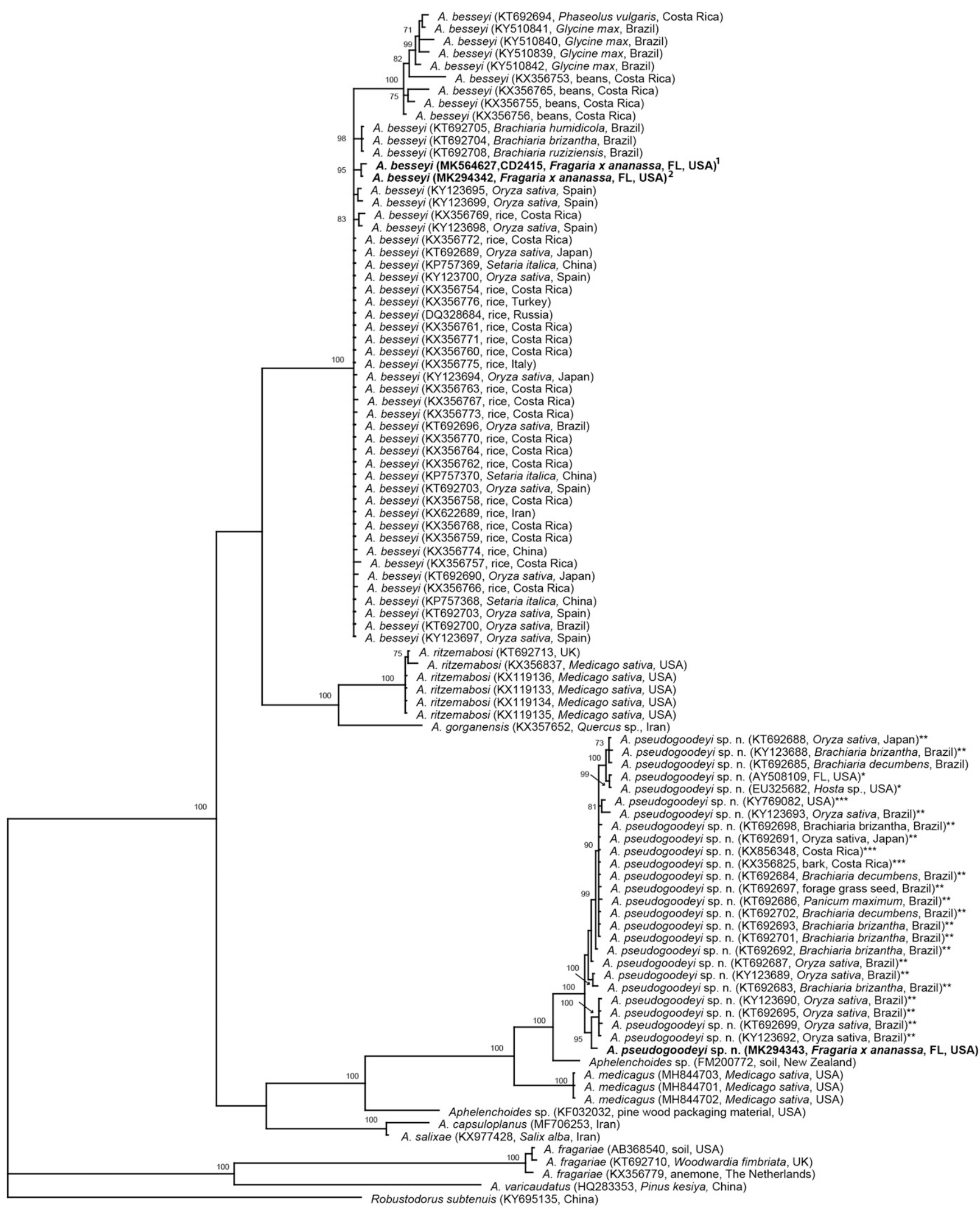

0.1

Fig. 8. Phylogenetic relationships within populations and species of the genus Aphelenchoides with stellate tails as inferred from Bayesian analysis using the D2-D3 of 28S rRNA gene sequence dataset with the GTR $+I+G$ model. Posterior probability more than $70 \%$ is given for appropriate clades. Newly obtained sequences are indicated in bold. Identified in the GenBank as *Aphelenchoides besseyi; ${ }^{* *}$ Aphelenchoides fujianensis; ${ }^{* *}$ Aphelenchoides sp. ${ }^{1}$ isolated from plant tissues; ${ }^{2}$ maintained on the fungus. 
gene variation between $A$. pseudogoodeyi sp. n. sequences range from 0 to $2.4 \%$, and between $A$. besseyi sequences reached up to $7.9 \%$.

COI gene. The COI gene alignment was $580 \mathrm{bp}$ in length and consisted of 67 sequences of Aphelenchoides and two sequences of Robustodorus subtenuis used as an outgroup taxon. The BI tree (Fig. 9) revealed eight clades: (i) two clades with sequences of A. besseyi populations, one with those from rice, strawberry, and
Brachiaria brizantha and a second one with those from fern (Asplenium nidus) from Taiwan; (ii) one clade with $A$. ritzemabosi; (iii) two clades with sequences of populations of $A$. pseudogoodeyi sp. n.: one from rice, bark, and Brachiaria spp. and another with the newly obtained sequence for A. pseudogoodeyi n. sp. from strawberry and other sequences of populations from Brachiaria spp. fern, Hosta sp., strawberry and others; (iv) one clade with one sequence of A. fujianensis; (v) one clade with A. medicagus from alfalfa, USA;

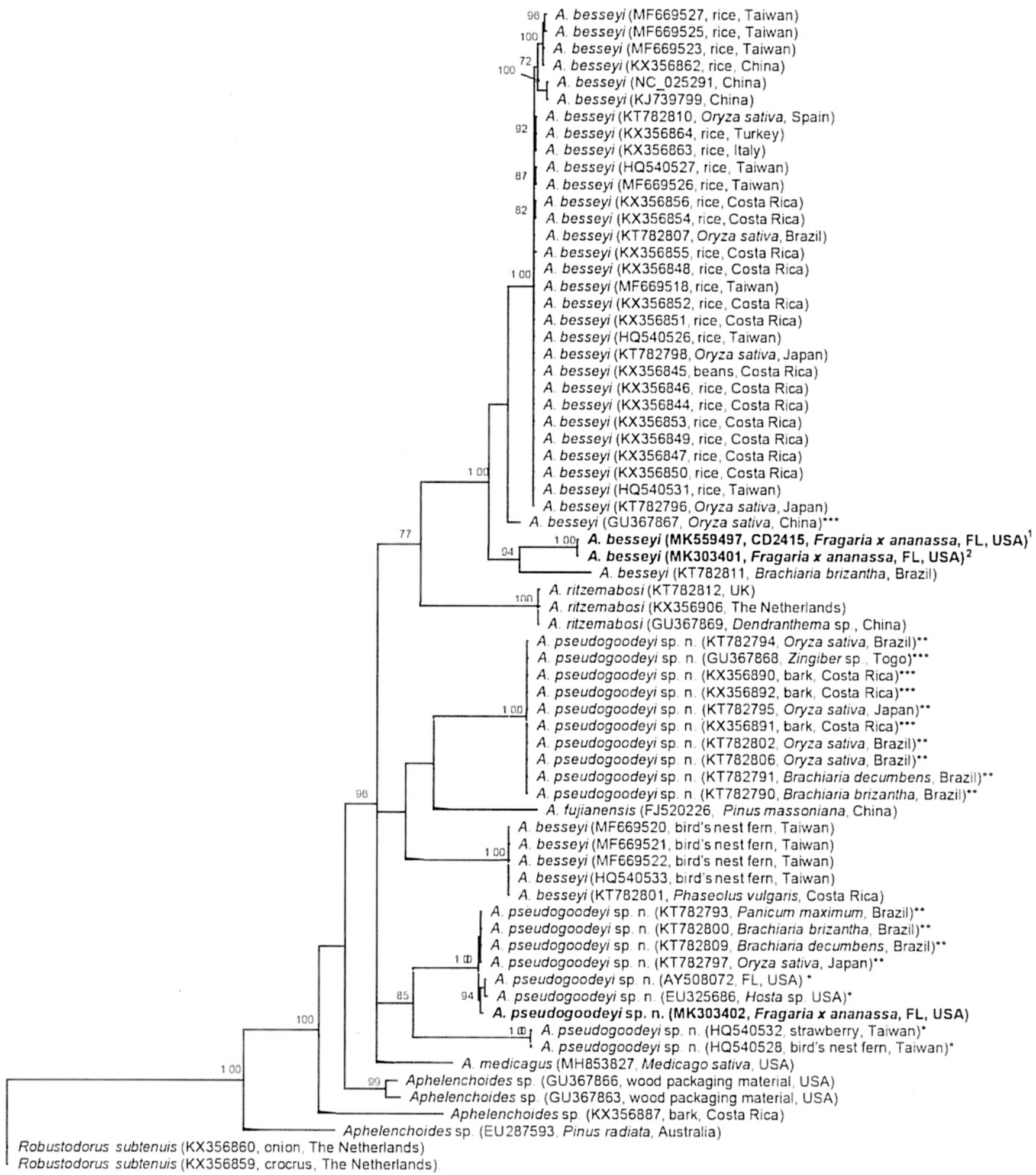
0.1

Fig. 9. Phylogenetic relationships within populations and species of the genus Aphelenchoides with stellate tails as inferred from Bayesian analysis using the $\mathrm{CO} /$ gene sequence dataset with the GTR $+I+G$ model. Posterior probability more than $70 \%$ is given for appropriate clades. Newly obtained sequences are indicated in bold. Identified in the GenBank as *Aphelenchoides besseyi; ${ }^{* *}$ Aphelenchoides fujianensis; ${ }^{* *}$ Aphelenchoides sp. ${ }^{1}$ isolated from plant tissues; ${ }^{2}$ maintained on the fungus. 
(vi) the clade with an unidentified Aphelenchoides sp. from wood packing materials, USA; (vii) the clade with Aphelenchoides sp. from bark, Costa Rica; and (viii) the clade with Aphelenchoides sp. from Pinus radiata. Interspecific $C O I$ gene sequence variation between $A$. pseudogoodeyi sp. n. and A. fujianensis was 14.6 to $15.3 \%$, whereas intraspecific variation for $A$. pseudogoodeyi sp. n. reached up to $17.2 \%$.

Phytoparasitic habits. Florida population of $A$. besseyi reinfected strawberry plants and attained their highest reproduction rates in gerbera daisy seedlings. There was variability in the final nematode population among strawberry plants that resulted in a mean value lower than that in gerbera (342 vs. 1,205). A smaller mean value (122) was also observed in strawberry from the repeated experiment. The symptoms observed in the infected strawberry plants were more accentuated in the inner than the outer leaves and consisted of crinkling, distortion, and spider-like appearance (Fig. 10A), as reported in the literature (Desaeger and Noling 2017). The symptoms of nematode infection on gerbera daisy were like those seen in the nematodeinfected strawberries (Fig. 10B). A very small population (27 specimens) was recorded from soybean. Alfalfa seedlings were not infected or damaged by the nematode. No nematodes were found in the soil of the pots regardless of the plant species (Table 5). Pots with alfalfa were an exception, because a residual population of 27 specimens persisted in their soil at the end of the experiment. No above-ground plant weight suppression was observed in all the treatments at the inoculation levels used.

Low final densities of the Florida population of A. pseudogoodeyi sp. $\mathrm{n}$. were observed in all the treatments at the two inoculation levels (Table 6). The largest population was observed on alfalfa at the highest inoculum level of 1,000 and did not exceed 35 specimens per plant top. No above-ground symptoms were observed regardless of the inoculum levels used. However, this nematode penetrated the trichomes that cover the stem of soybean (Fig. 11). The mean nematode densities in live soybean plants, at the highest inoculum level $(1,000)$ just 19 specimens per plant top 60 DAI, equivalent to two specimens per gram of fresh plant tissues. By contrast, an average of 553 nematodes were extracted from desiccated stem tissues in an extra set of seedlings inoculated with 1,000 specimens but kept in the greenhouse for 130 DAI until they died (data not shown).

Localized inoculation of $A$. pseudogoodeyi sp. n. on soybean leaves. Definitive proof of phytoparasitism by putative $A$. pseudogoodeyi sp. $\mathrm{n}$. was obtained from the results of the inoculation test of soybean leaves with pieces of filter paper containing specimens of this nematode. The portion of the leaves in contact with the nematode-infested filter paper became discolored and reddish 30 days after the paper filter application. These discolored areas were $7 \mathrm{~mm}$ long and $6 \mathrm{~mm}$ wide. Necrosis of the mesophyll was also observed in these areas (Fig. 12A and B). Examination of the discolored leaf areas using a stereomicroscope allowed the observation of the nematodes inside the palisade and spongy parenchyma tissues of the mesophyll after tearing the leaf epidermis with a needle (Fig. 13). The number of nematodes found inside these discolored areas of the leaves varied from two to five (data not reported in table). These lesions, however, did not expand after leaving the plants in the greenhouse for 2 additional weeks or 38 DAI.

\section{Discussion}

Phylogenetic and sequence analysis of three genes of $A$. besseyi populations studied and identified in our work revealed a high intraspecific diversity and presence of at least three distinct groups. The

Table 5. Final plant top and soil population densities of Aphelenchoides besseyi extracted from alfalfa, gerbera, soybean, and strawberry 60 days after inoculation; fresh plant top weights of each crop at plant harvest are shown in the last column ${ }^{\mathbf{x}}$

\begin{tabular}{lcccr}
\hline Crop & $\begin{array}{c}\text { Inoculum } \\
\text { levels }\end{array}$ & $\begin{array}{c}\text { Nematodes/ } \\
\text { plant top }\end{array}$ & $\begin{array}{c}\text { Nematodes/200 g } \\
\text { of soil }\end{array}$ & $\begin{array}{c}\text { Fresh plant } \\
\text { weight }^{\mathbf{z}}\end{array}$ \\
\hline Alfalfa & 0 & 0 & $0 \mathrm{~b}$ & $5.5 \pm 0.3 \mathrm{a}$ \\
Gerbera & 600 & 0 & $27 \pm 16.9 \mathrm{a}$ & $5.3 \pm 0.5 \mathrm{a}$ \\
& 0 & $0 \mathrm{~b}$ & 0 & $23.7 \pm 2.3 \mathrm{a}$ \\
Soybean & 600 & $1205 \pm 1193 \mathrm{a}$ & 0 & $23.5 \pm 0.9 \mathrm{a}$ \\
& 0 & $0 \mathrm{~b}$ & 0 & $15.2 \pm 1.3 \mathrm{a}$ \\
Strawberry & 600 & $27 \pm 16.9 \mathrm{a}$ & 0 & $18.5 \pm 0.6 \mathrm{a}$ \\
& 0 & $0 \mathrm{~b}$ & 0 & $15.6 \pm 1.5 \mathrm{a}$ \\
Strawberry & 000 & $342 \pm 153.2 \mathrm{a}$ & 0 & $8.6 \pm 1.1 \mathrm{a}$ \\
repeated & 600 & $0 \mathrm{~b}$ & 0 & $6.4 \pm 0.5 \mathrm{a}$ \\
treatment & & $122 \pm 29.3 \mathrm{a}$ & 0 & \\
\hline
\end{tabular}

$\mathrm{x}$ Values are mean of five replicates. Column means for each crop followed by common letters are not different according to the Kruskal-Wallis nonparametric test $(P=0.05)$. In the repeated strawberry treatment, plantlets were enclosed in cages screened with a $4-\mu \mathrm{m}$-pore net for protection from noxious arthropods.

${ }^{y}$ Nematode densities are expressed as total number of nematodes extracted from the entire plant top.

$\mathrm{z}$ Values of plant top weights are expressed in grams.
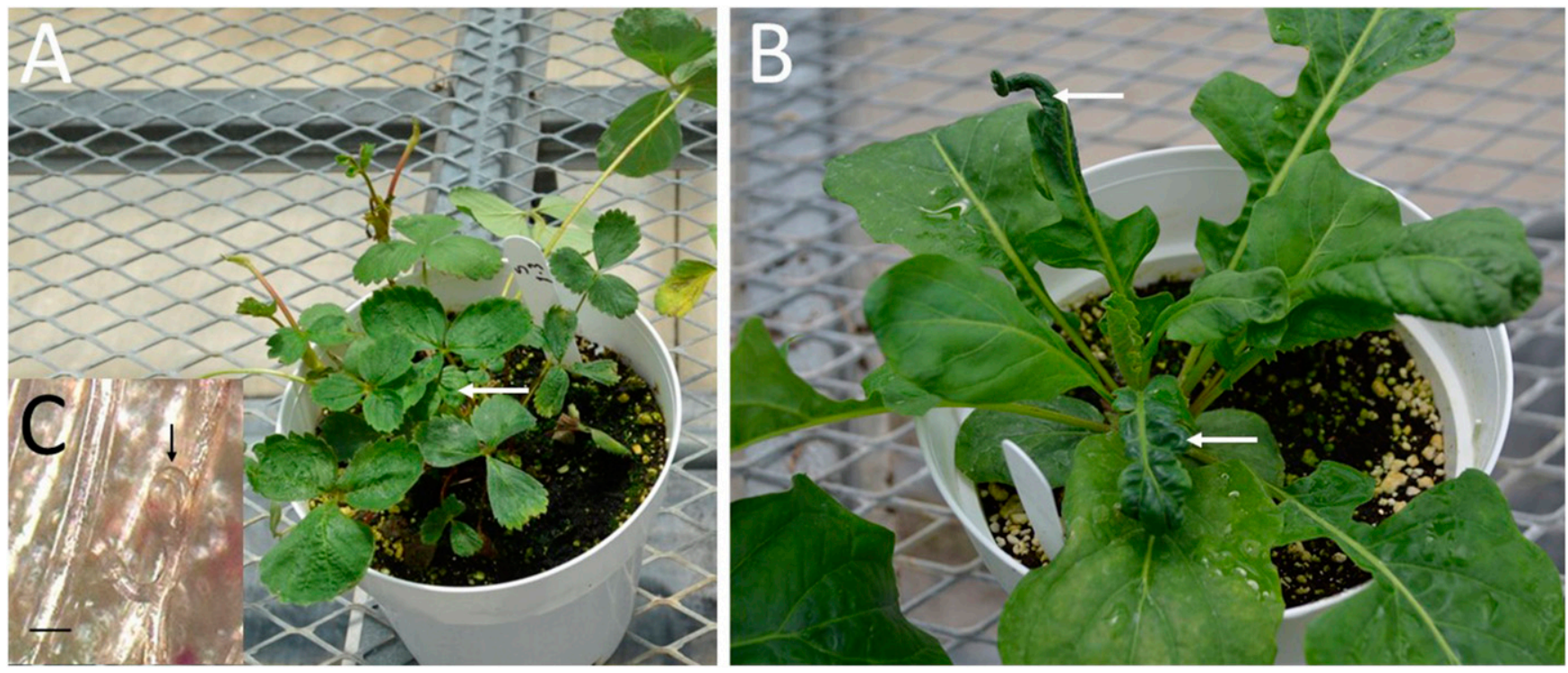

Fig. 10. Symptoms induced by Aphelenchoides besseyi. A, Plantlet of strawberry cultivar Florida Radiance showing crinkled and distorted leaves (arrow) 60 days after the inoculation with 600 nematodes. B, Small plant of gerbera daisy showing distorted, deformed, and dwarfish leaves (arrow) 60 days after inoculation with 600 nematodes. C, A coiled nematode specimen on the surface of the blade of a strawberry leaflet where it feeds ectoparasitically (arrow). Scale bar $=30 \mu \mathrm{m}$. 
sequence of the A. besseyi from Florida strawberry and those of other populations of this species reported in the literature are not identical and demonstrate that $A$. besseyi is a species complex. The populations that were used for comparison in this study originated from distant geographical areas. Our Florida strawberry population originated from strawberry stolons imported from a strawberry nursery in Cashiers, North Carolina, approximately 200 miles west of Willard, North Carolina, the type locality of $A$. besseyi. We consider this population morphologically closest to that of $A$. besseyi described by Christie in 1942. Unfortunately, no DNA sequences are available for any other samples, which could be considered as the type population of $A$. besseyi. Some published sequences for the three loci $18 \mathrm{~S}$ rRNA, 28S rRNA, and COI (AY508035, 508109, and 508072) from another Florida population from strawberry were identified as $A$. besseyi by Ye et al. (2007), but in the phylogenetic trees this population clusters in the same clade with $A$. pseudogoodeyi sp. n. and is considered conspecific. The new sequences obtained for $A$. besseyi in this study are the only sequences representative of this species in Florida. Our study confirms the reoccurrence of $A$. besseyi in Florida strawberry fields and validates the identification of this nematode on strawberries reported in previous studies by Desaeger and Noling (2017) and Oliveira et al. (2018). This population behaved as a facultative phytoparasite by reproducing on both strawberries and the fungus $M$. fructicola. The morphology of these two isolates from the two different food sources did not differ, although an adverse effect of the fungus on the body size of the males was observed. The males from our cultures were smaller than those reported in the literature. A similar effect from the fungus in inducing small body size was reported by Fortuner (1970) on males cultured on the fungus A. oleracea. In our $M$. fructicola cultures, males remained active for 23 days and died soon after, whereas females remained alive for almost 2 months. These surviving females were active and showed the spermatheca packed with sperm. The results of phylogenetic analyses using sequences for the three loci $18 \mathrm{~S}$ rRNA, 28S rRNA, and $C O I$ of $A$. besseyi populations from different hosts

Table 6. Final plant top and soil population densities of a population of Aphelenchoides pseudogoodeyi sp. n. extracted from alfalfa, gerbera, soybean, and strawberry, 60 and 84 (gerbera only) days after inoculation with various inoculum levels; fresh plant top weights of each crop at plant harvest are shown in the last column ${ }^{\mathrm{x}}$

\begin{tabular}{lrccl}
\hline Crop & $\begin{array}{c}\text { Inoculum } \\
\text { levels }\end{array}$ & $\begin{array}{c}\text { Nematodes/ } \\
\text { plant top }\end{array}$ & $\begin{array}{c}\text { Nematodes/ } \\
\text { 200 g of soil }\end{array}$ & $\begin{array}{c}\text { Fresh plant } \\
\text { weight }^{\mathbf{z}}\end{array}$ \\
\hline Alfalfa & 0 & $0 \mathrm{~b}$ & $0 \mathrm{c}$ & $12 \pm 1.4 \mathrm{a}$ \\
& 400 & $10 \pm 6.5 \mathrm{a}$ & $245 \pm 85.5 \mathrm{a}$ & $16.3 \pm 2.6 \mathrm{a}$ \\
& 1000 & $6.4 \pm 3 \mathrm{a}$ & $96 \pm 31.6 \mathrm{~b}$ & $17.3 \pm 1.7 \mathrm{a}$ \\
Alfalfa & 0 & $0 \mathrm{~b}$ & $0 \mathrm{~b}$ & $35 \pm 6.3 \mathrm{a}$ \\
repeated & 400 & $19 \pm 9 \mathrm{a}$ & $11 \pm 4.6 \mathrm{a}$ & $42.4 \pm 10 \mathrm{a}$ \\
treatment & 1000 & $34 \pm 7.3 \mathrm{a}$ & $6.0 \pm 1.6 \mathrm{a}$ & $40.5 \pm 6.3 \mathrm{a}$ \\
Gerbera & 0 & $0 \mathrm{~b}$ & $0 \mathrm{~b}$ & $13.7 \pm 5.7 \mathrm{a}$ \\
& 400 & $3 \pm 0.8 \mathrm{a}$ & $5 \pm 0.4 \mathrm{a}$ & $19.3 \pm 2.7 \mathrm{a}$ \\
Soybean & 1000 & $4 \pm 1.2 \mathrm{a}$ & $16.6 \pm 9.8 \mathrm{a}$ & $13 \pm 5.7 \mathrm{a}$ \\
& 0 & $0 \mathrm{~b}$ & $0 \mathrm{c}$ & $34.8 \pm 1.1 \mathrm{a}$ \\
Soybean & 400 & $15 \pm 10.7 \mathrm{a}$ & $28 \pm 9.7 \mathrm{~b}$ & $39 \pm 4.5 \mathrm{a}$ \\
repeated & 1000 & $19 \pm 11.6 \mathrm{a}$ & $139 \pm 34.3 \mathrm{a}$ & $39.4 \pm 1.6 \mathrm{a}$ \\
treatment & 0 & $0 \mathrm{~b}$ & $0 \mathrm{~b}$ & $37.1 \pm 2.3 \mathrm{a}$ \\
Strawberry & 1000 & $15 \pm 5.7 \mathrm{a}$ & $4 \pm 2.9 \mathrm{ab}$ & $32.4 \pm 1.5 \mathrm{a}$ \\
& 0 & $0 \mathrm{~b}$ & $0 \mathrm{~b}$ & $55.1 \mathrm{a} \pm 3 \mathrm{a}$ \\
& 400 & $11 \pm 9.3 \mathrm{a}$ & $30 \pm 11.8 \mathrm{a}$ & $45.9 \pm 7.8 \mathrm{a}$ \\
& 1000 & $16 \pm 13 \mathrm{a}$ & $19 \pm 14 \mathrm{ab}$ & $46.3 \pm 11.2 \mathrm{a}$ \\
\hline
\end{tabular}

$\mathrm{z}$ Values are mean of five replicates. Column means for each crop followed by common letters are not different according to the Kruskal-Wallis nonparametric test $(P=0.05)$. In repeated treatments of alfalfa and soybean, seedlings were enclosed in cages screened with a $4-\mu \mathrm{m}$-pore net for protection from noxious arthropods.

${ }^{y}$ Nematode densities are expressed as total number of nematodes extracted from the entire plant top.

${ }^{x}$ Values of plant top weights are expressed in grams. indicate that the sequences of populations from rice and leguminous plants cluster in different clades from those of the strawberry populations, suggesting that they might be different taxa. More biological, morphological, and phylogenetic studies are needed to clarify the taxonomic status of $A$. besseyi populations from different hosts. In the host study, the populations from $M$. fructicola cultures maintained their phytoparasitic behavior and parasitized strawberry and other selected plant species. Strawberry and gerbera daisy were the most suitable hosts compared with soybean and alfalfa. The smaller population levels in strawberry compared with gerbera daisy may be because of the different morphology of the leaves of the two hosts. The large leaves of gerbera daisy retained more initial inoculum than the small leaves of strawberries, resulting in greater final population levels in the tissues of this flowering ornamental plant than in those of the strawberry plants. The nematode behaved as an ectoparasite on strawberry, as reported by Christie (1959), and on gerbera daisy, which is reported as new host of A. besseyi. Very low population levels were observed in soybean, indicating that this legume is not a host of the Florida population of A. besseyi under the conditions of this experiment. Alfalfa was not infested by the nematode, confirming the selective host preference of this Florida population of $A$. besseyi. Our study shows that the initial inoculation levels that we used in the greenhouse experiments were sufficient to produce plant infection when delivered directly on the plant top. These inoculum levels were as effective as those of 400 specimens applied in the soil in the inoculation tests conducted by Marlatt and Perry (1971). Our results suggest that $A$. besseyi has the potential to become an emerging problem for

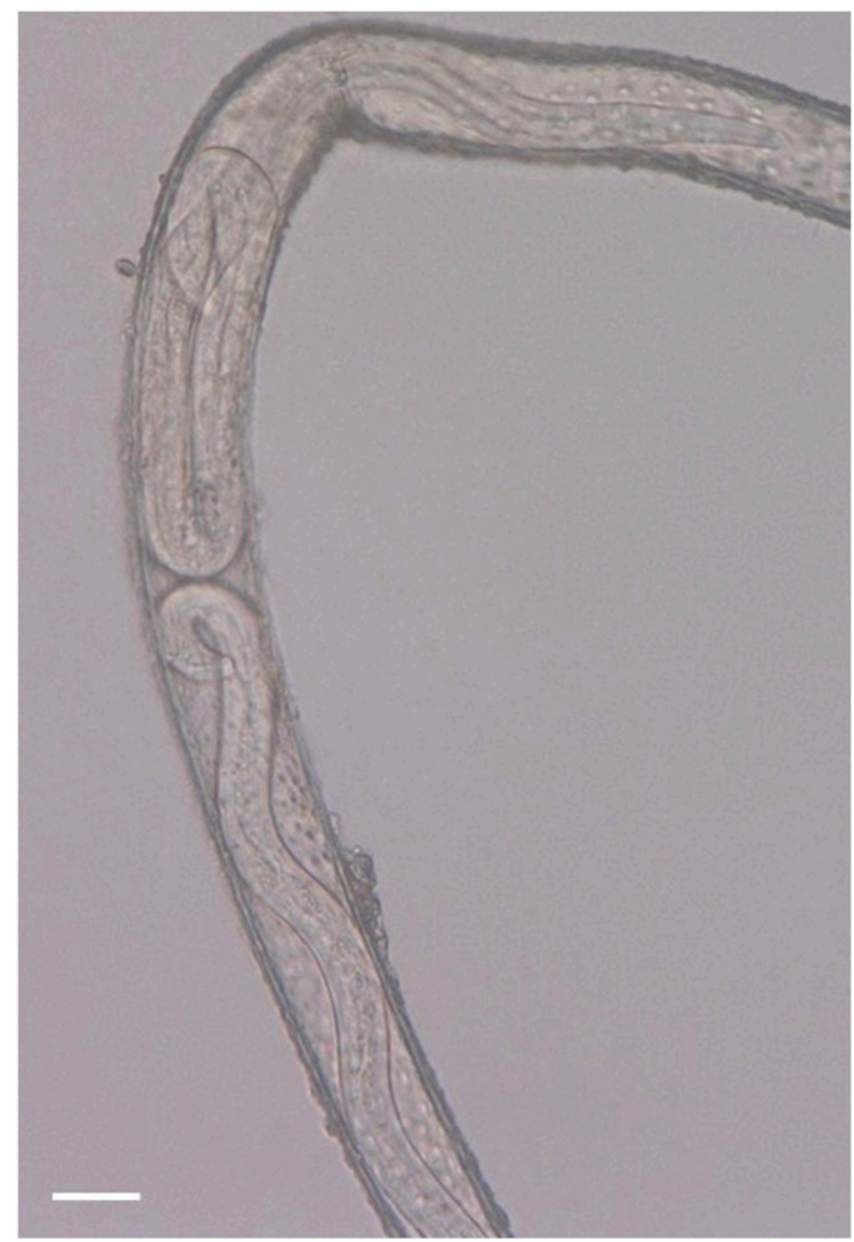

Fig. 11. Aphelenchoides pseudogoodeyi sp. $\mathrm{n}$. on soybean. Nematode specimens inside a trichome of the stem of a soybean seedling 60 days after the inoculation of 1,000 nematodes in an aqueous suspension delivered in droplets on the surface and petiole of its leaves. Scale bar $=39 \mu \mathrm{m}$. 
Florida strawberry growers. However, it is not certain that this nematode will become as serious a problem as it was 50 years ago, because the infections of the nematode observed in the field in 2018 were less serious than those in 2017. Reoccurrence of nematode infections has been observed again in the season 2018/2019, but overall damage and yield loss appeared minimal. The epidemiology of this foliar nematode on strawberries should be investigated for more years in Florida fields.

This study demonstrates that the Florida population and populations from other countries named as 'A. fujianensis' were incorrectly identified by de Jesus et al. (2016) and Oliveira et al. (2018). Rather, these populations are the new species A. pseudogoodeyi sp. n., which belongs to the Group 3 of Aphelenchoides with stellate tail as defined by Shahina (1996). This new species is well defined and can be separated both morphologically and molecularly from other described Aphelenchoides species, including the type A. fujianensis from China. The populations identified as 'A. fujianensis' from Brazil, Costa Rica, and Japan (De Jesus et al. 2016) show high variability in their morphometrics that complicates their separation from the type A. fujianensis; however, the arrangement of the oocytes in multiple unaligned rows in the short ovary and the lack of a functional spermatheca in their females, along with the absence of males, are the most important morpho-biological characters that they share with A. pseudogoodeyi sp. n. and separate them from the type A. fujianensis. The results of the phylogenetic analysis using the 18S rRNA, 28S rRNA, and $C O I$ gene sequences confirmed that these populations of ' $A$. fujianensis' identified by de Jesus et al. (2016) from distant geographical areas are conspecific with Floridian A. pseudogoodeyi sp. n. and are indicated with this new name in the phylogenetic trees.

Under the field conditions of Florida, A. pseudogoodeyi $\mathrm{sp} . \mathrm{n}$. is associated with $A$. besseyi in senescent strawberry plants. These two species are morphologically and behaviorally different: Aphelenchoides besseyi is a facultative phytoparasite, whereas A. pseudogoodeyi sp. n. is mainly mycetophagous. This new species, however, can become phytophagous in stressful conditions. The localized inoculation of the nematodes applied with pieces of filter paper adhering to the blade of the soybean leaves resulted in nematode penetration of the epidermis and invasion of the mesophyll with subsequent development of symptoms like those reported for other foliar nematodes. However, the population levels observed in the host test were low and less than two specimens per gram of fresh tissues. On the contrary, population densities of the nematode in soybean senescent tissues were 20 -fold greater because the nematode most likely developed and reproduced on its preferred Fusarium spp., Trichoderma spp., and Colletotrichum spp. that were isolated from the inside and outside of the dead soybean stem. Our work showed that this A. pseudogoodeyi sp. n.

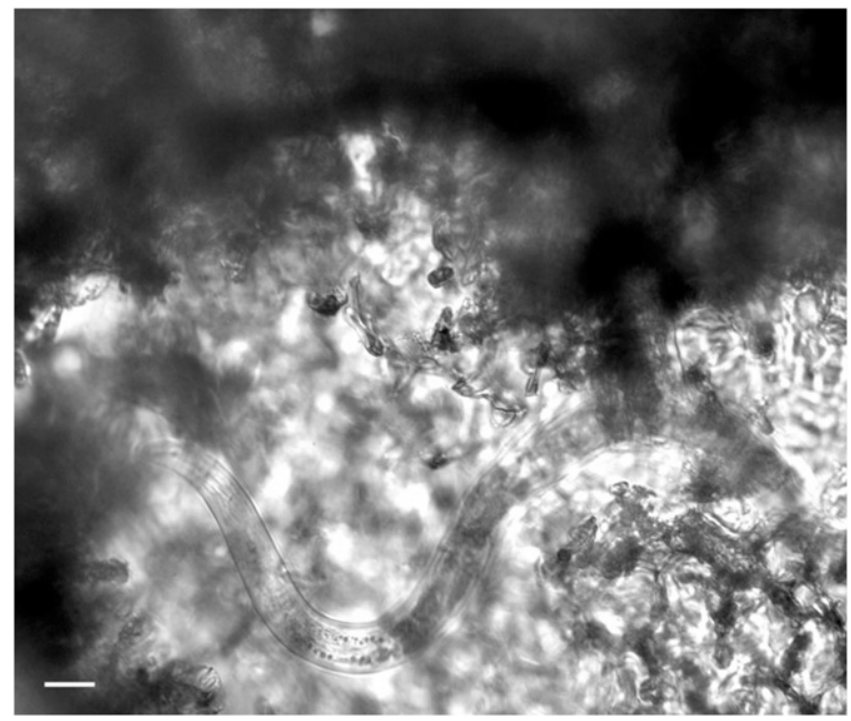

Fig. 13. Aphelenchoides pseudogoodeyi sp. $\mathrm{n}$. inside soybean leaf tissues. Note a nematode specimen tunneling the mesophyll 24 days after the inoculation of 300 specimens delivered with a piece of filter paper attached to the leaf blade. Scale bar $=24 \mu \mathrm{m}$.
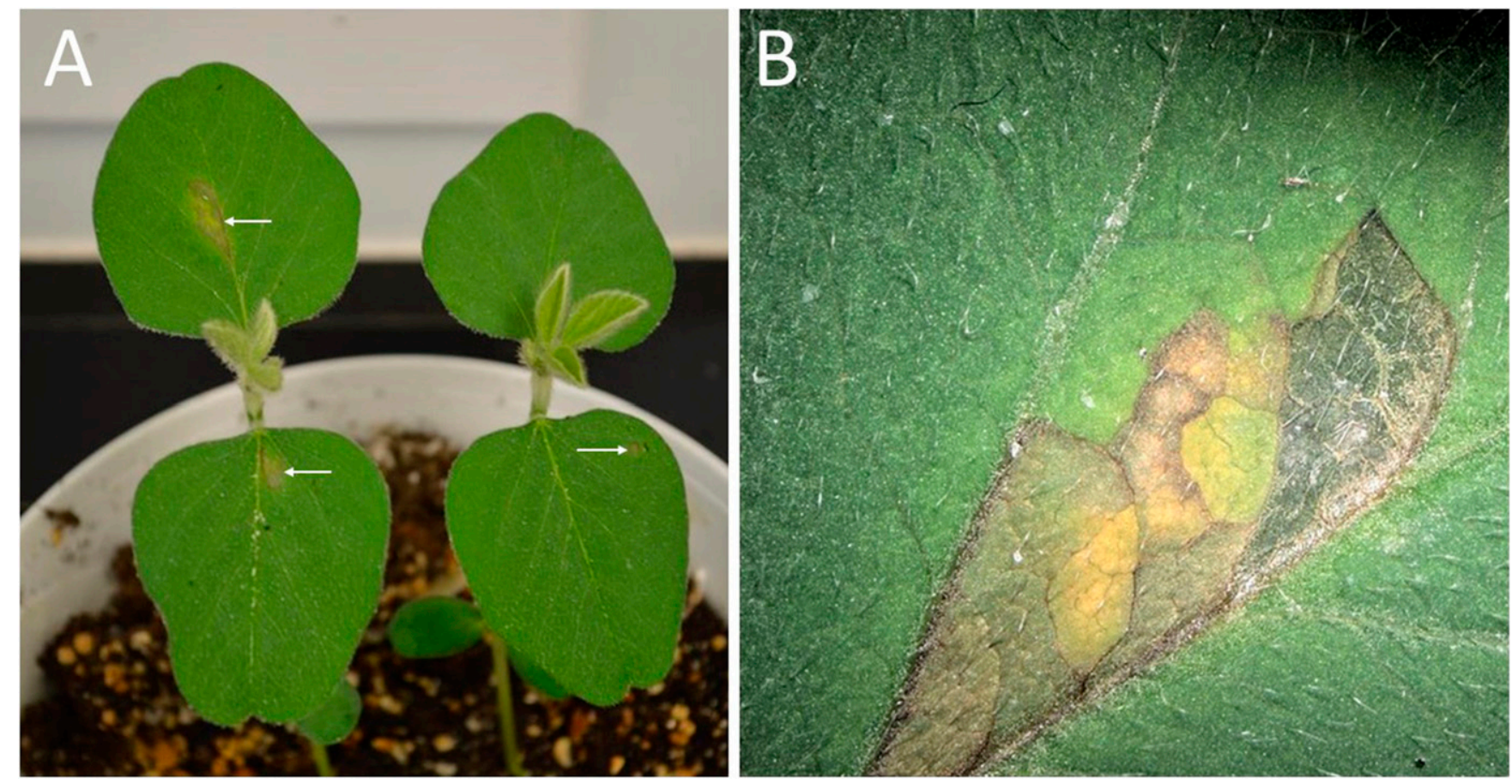

Fig. 12. Symptoms induced by Aphelenchoides pseudogoodeyi sp. n. on soybean leaves. A, Plants showing lesions (arrows) on the upper surface of the blade 9 days after inoculation of the nematode that was applied with pieces of filter paper attached to the leaf blade. B, Closeup of the lesion delimited by the veins of the leaflet showing chlorotic and desiccated areas and dark tissues along the veins. 
does not have the aggressiveness and phytoparasitic abilities of economically important foliar nematodes such as A. besseyi, A. fragariae, and A. ritzemabosi.

\section{Acknowledgments}

This research paper is an expanded version of a thesis submitted by the first author to the Viçosa Federal University, Viçosa, MG, Brazil to fulfill the requirements for the Master of Science Degree in Plant Pathology. The authors acknowledge the technical support provided by Justin Carter, Dr. Paul Dahlin, Bruno de Marchi, David Moreira, Hailey Regier, Marco Suárez, Bonnie Xie, and Dr. Tristan Watson, University of Florida, Gulf Coast Research and Education Center, Wimauma, Florida; Jhonatan Barros, Department of Plant Pathology, Viçosa Federal University, Viçosa, Brazil; and Sai Qiu, Florida Department of Agriculture and Consumer Services, Gainesville, Florida. The authors thank Dr. Larry W. Duncan for comments and suggestions during manuscript draft preparation.

\section{Literature Cited}

Allen, M. W. 1952. Taxonomic status of the bud and leaf nematodes related to Aphelenchoides fragariae (Ritzema Bos, 1891). Proc. Helminth. Soc. Wash. 19:108-120.

Andrássy, I. 1959. Neue und wenig bekannte Nematoden aus Jugoslawien. Annls hist.-nat. Mus. Natn. Hung. 51:259-275.

Andràssy, I. 1968. Fauna Paraguayensis. 2. Nematoden aus den Galeriewäldern des Acaray Flusses. Opusc. Zool. Bpest. 8:167-315.

Bird, A. F., Bird, J., Fortuner, R., and Moen, R. 1989. Observations on Aphelenchoides hylurgi Massey, 1974 feeding on fungal pathogens of wheat in Australia. Revue Nematol. 12:27-34.

Brooks, A. N. 1931. Crimp-A nematode disease of strawberry. University of Florida Agricultural Experiment Station. Annual Report 1931. Florida Agr. Exp. Sta. Bull. 235:1-27.

Chizhov, V. N., Chumakova, O. A., Subbotin, S. A., and Baldwin, J. G. 2006. Morphological and molecular characterization of foliar nematodes of the genus Aphelenchoides: A. fragariae and A. ritzemabosi (Nematoda: Aphelenchoididae) from the Main Botanical Garden of the Russian Academy of Sciences, Moscow. Russ. J. Nematol. 14:179-184.

Christie, J. R. 1932. Recent observations on the strawberry dwarf nematode in Massachusetts. Plant Dis. Rep. 16:113-114.

Christie, J. R. 1938. Two distinct strains of the nematode Aphelenchoides fragariae occurring on strawberry plants in the United States. J. Agric. Res. 57:73-80.

Christie, J. R. 1942. A description of Aphelenchoides besseyi n. sp., the summer dwarf nematode of strawberries, with comments on the identity of Aphelenchoides subtenuis (Cobb, 1929) and Aphelenchoides hodsoni Goodey, 1935. Proc. Helminth. Soc. Wash. 9:82-84.

Christie, J. R. 1959. Plant Nematodes, Their Bionomics and Control. Agricultural Experiment Stations. University of Florida, Gainesville, Florida.

Das, V. M. 1960. Studies on the nematode parasites of plants in Hyderabad (Andhra Pradesh, India). Ztschr. Parasitenk. 19:553-605.

de Jesus, D. S., Oliveira, C. M. G., Roberts, D., Block, V., Prior, T., Balbino, H. M., MacKenzie, K. M., and Oliveira, R. D. 2016. Morphological and molecular characterization of Aphelenchoides besseyi and A. fujianensis (Nematoda: Aphelenchoididae) from rice and forage grass seeds in Brazil. Nematology 18:337-356

Desaeger, J., and Noling, J. 2017. Foliar and bud nematodes in Florida strawberries. (ENY-068). Gainesville: University of Florida Institute of Food and Agricultural Sciences. https://edis.ifas.ufl.edu/pdffiles/IN/IN118400.pdf

Eroshenko, A. S. 1967. Three new species of the genus Aphelenchoides Fischer, 1894 (Nematoda: Aphelenchoididae). Zoologicheskii Zhurnal 46:617-620 (in Russian).

Esmaeili, M., Fang, Y., Li, H., and Heydari, R. 2016. Description of Aphelenchoides huntensis sp. N. (Nematoda: Aphelenchoididae) isolated from Pinus silvestris in western Iran. Nematology 18:357-366.

Esser, R. P. 1986. A water agar en face technique. Proc. Helminth. Soc. Wash. 53: 254-255

Fang, Y., Gu, J., Wang, X., and Li, H. 2014. Description of Aphelenchoides stellatus n. sp. (Nematoda: Aphelenchoididae) found in packaging wood from Japan. Nematology 16:621-630.

Favoreto, L., and Meyer, M. C. 2017. "Soya Louca II" - Green stem and foliar retention - a new soybean disease in Brazil. Nematropica 47: ABST. 13.

Favoreto, L., Meyer, M. C., Calandrelli, A., da Silva, M. C. M., and da Silva, S. A. 2017. "Soya Louca II" - First study of the host-pathogen relationship. Nematropica 47: ABST. 13.

Filipjev, I. N. 1934. Harmful and useful nematodes in rural economy. OGIZSel'khozgiz, Moskva-Leningrad, Russia.

Filipjev, I. N., and Schuurmans Stekhoven, J. H., Jr. 1941. A Manual of Agricultural Helminthology. Brill, Leiden, The Netherlands.

Floyd, R., Abebe, E., Papert, A., and Blaxter, M. 2002. Molecular barcodes for soil nematode identification. Mol. Ecol. 11:839-850.

Fortuner, R. 1970. On the morphology of Aphelenchoides besseyi (Christie, 1942) and A. siddiqii n. sp. (Nematoda: Aphelenchoidea). J. Helminthol. 44:141-152.
Franklin, M. T., and Siddiqi, M. R. 1972. Aphelenchoides besseyi. In: CIH Descriptions of Plant-parasitic Nematodes. Set 1. No. 4, 3 pp. CAB International, Wallingford, UK

Giblin-Davis, R. M., Gerber, K., and Griffith, R. 1989. In vivo and in vitro culture of the ring nematode, Radinaphelenchus cocophilus. Nematropica 19 135-142.

Golhasan, B., Fang, Y., Li, H., Tanha Maafi, Z., and Heydari, R. 2019. Description of Aphelenchoides tabarestanensis n. sp. (Nematoda: Aphelenchoididae) isolated from Pinus brutia in Northern Iran. Nematology 21:159-169.

Gray, F. A., Williams, F. L., Griffin, G. D., and Wilson, T. E. 1994. Distribution in the Western United States on alfalfa and cultivar reaction to mixed populations of Ditylenchus dipsaci and Aphelenchoides ritzemabosi. J. Nematol. 26 (Suppl.):705-719

Holterman, M., Karssen, G., van den Elsen, S., van Megen, H., Bakker, J., and Helder, J. 2009. Small subunit rDNA-based phylogeny of the Tylenchida sheds light on relationships among some high-impact plant parasitic nematodes and the evolution of plant feeding. Phytopathology 99:227-235.

Hunt, D. J. 1993. Aphelenchida, Longidoridae and Trichodoridae: Their systematics and bionomics. CAB International, Wallingford, UK.

Hunt, D. J. 2007. A checklist of Aphelenchoidea (Nematoda: Tylenchina). J Nematode Morphol. Syst. 10:99-135.

Husain, S. I., and Khan, A. M. 1967. On the status of the genera in the superfamily Aphelenchoidea (Fuchs, 1937) Thorne, 1949 with the description of six new species of nematodes from India. Proc. Helminth. Soc. Wash. 34:167-174.

Imamura, S. 1931. Nematodes in the paddy field, with notes on their population before and after irrigation. J. Coll. Agric. Imp. Univ. Tokyo 11:193-240.

Jain, V. K., and Singh, S. P. 1984.Two new species of Aphelenchoides (Nematoda: Aphelenchoididae) from India. Bull. Ent. 25:135-142.

Kanzaki, N., and Futai, K. A. 2002. A PCR primer set for determination of phylogenetic relationships of Bursaphelenchus species within the xylophilus group. Nematology 4:35-41.

Lehman, P. S. 2002. Phytoparasitic nematodes reported from Florida. Florida Department of Agriculture and Consumer Services, Division of Plant Industry, Gainesville, FL. https://freshfromflorida.s3.amazonaws.com/phyotnema.pdf.

Lisetskaya, L. F. 1971. Aphelenchoides menthae n. sp. (Nematoda: Aphelenchoididae). Parazity Zhivotnykh i Rastenii 6:123-126.

Liu, W., Wu, X., Duan, Y., and Liu, Y. 1999. A new species of genus Aphelenchoides, leaf nematode of American ginseng, Aphelenchoides panaxofolia n. sp. (Nematoda: Aphelenchoidae). Acta Phytopathol. Sin. 29: 360-363.

Loos, C. A. 1941. Some diseases of garden plants. Trop. Agric. Mag. Ceylon Agric. Soc. 96:22-27.

Marlatt, R. B. 1970. Transmission of Aphelenchoides besseyi to Ficus elastica leaves via Sporobolus poiretii inflorescences. Phytopathology 60:543-544.

Marlatt, R. B., and Perry, V. G. 1971. Growth stimulation of Sporobolus poiretii by Aphelenchoides besseyi. Phytopathology 61:740.

Massey, C. L. 1974. Biology and taxonomy of nematode parasites and associates of bark beetles in the United States. Forest Service, USDA, Washington. https:// searchworks.stanford.edu/view/10632625

Miraeiz, E., Haydari, R., and Bert, W. 2017. Aphelenchoides gorganensis n. sp. (Nematoda: Aphelenchoididae), a new species from Iran. Eur. J. Plant Pathol. 149:157-169.

Mobasseri, M., Pourjam, E., and Pedram, M. 2018. Morphological and molecular characterisation of Aphelenchoides primadentus n. sp. (Nematoda: Aphelenchoididae) from northern Iran. Nematology 20:97-109.

Nesterov, P. I. 1973. New species of plant nematodes from the arctic tundra of the USSR (Yamal Peninsula). Izv. Akad. Nauk Kazakhskoi SSR 4:68-70.

Nunn, G. B. 1992.Nematode Molecular Evolution. Ph.D. dissertation. University of Nottingham, Nottingham, UK.

Oliveira, C., Desaeger, J., Watson, T., Vau, S., Freitas, L. G., and Inserra, R. N 2018. Identification of Aphelenchoides spp. associated with strawberries in Florida. Nematropica 48: ABST. 31

Posada, D. 2008. jModelTest: Phylogenetic model averaging. Mol. Biol. Evol. 25: $1253-1256$

R Core Team. 2017. R: A language and environment for statistical computing (Version 3.4.1) $\mathrm{R}$ foundation for statistical computing. Vienna, Austria https://R-project.org/

Riedel, R. M. 1985. Pathogenicity and reproduction of Aphelenchoides ritzemabosi and $A$. fragariae in Rieger begonia. Pages 127-128 in: Plant Nematology: Laboratory Manual. B. M. Zuckerman, W. F. Mai, and M. B. Harrsison, eds. University of Massachusetts Agricultural Experiment Station, Amherst, MA.

Ritzema-Bos, J. 1890. De bloemkoolziekte der aardbeien, veroorzaakt door Aphelenchoides fragariae nov. spec. (Voorloopige mededeeling). Maandbl. Naturwetensch. 16:107-117.

Rodríguez-Kábana, R., and Pope, M. H. 1981. A simple incubation method for the extraction of nematodes from soil. Nematropica 11:175-186.

Ronquist, F., and Huelsenbeck, J. P. 2003. MrBayes 3: Bayesian phylogenetic inference under mixed models. Bioinformatics 19:1572-1574.

Ronquist, F., Teslenko, M., van der Mark, P., Ayres, D. L., Darling, A., Höhna, S., Larget, B., Liu, L., Suchard, M. A., and Huelsenbeck, J. P. 2012. MrBayes 3.2 
Efficient Bayesian phylogenetic inference and model choice across a large model space. Syst. Biol. 61:539-542.

Sánchez-Monge, G. A., Jansen, T., Fang, Y., Couvreur, M., Karssen, G., and Bert,

W. 2017. Mt COI successfully diagnoses the four main plant-parasitic Aphelenchoides species (Nematoda-Aphelenchoididae) and supports multiple origin of plant-parasitism in tis polyphyletic genus. Eur. J. Plant Pathol. 148: 853-866.

Schwartz, M. 1911. Die Aphelenchen der Veilchengallen und der Blettflecken an Farnen und Chrysanthemum. Arb. K. Biol. Anstalt Land. u. Forstwirtsch. 8: 303-334.

Seinhorst, J. W. 1959. A rapid method for the transfer of nematodes from fixative to anhydrous glycerin. Nematologica 4:67-69.

Shahina, F. 1996. A diagnostic compendium of the genus Aphelenchoides Fisher, 1894 (Nematoda: Aphelenchida) with some new records of the group from Pakistan. Pak. J. Nematol. 14:1-32.

Siddiqi, M. R. 2000. Tylenchida parasites of plants and insects, 2nd Ed. C.A.B. International, Wallingford, UK

Siddiqi, M. R., and Franklin, M. T. 1967. Aphelenchoides goodeyi (Nematoda: Aphelenchoidea), a mycophagous nematode from South India. Nematologica 13:125-130.

Siddiqi, M. R., and Hawksworth, D. L. 1982. Nematodes associated with galls on Cladonia glauca, including two new species. Lychenologist 14:175-184.

Siddiqi, M. R., Husain, Z., and Khan, A. M. 1967. Seinura propora n. sp. and Aphelenchoides alighariensis n. sp. (Nematoda: Aphelenchoididae) from North India. Nematologica 13:287-290.

Siddiqui, I. A. 1976. Aphelenchoides bicaudatus. In: CIH Descriptions of Plantparasitic Nematodes. Set 6. No. 84, 3 pp.Commonwealth Institute of Helminthology, St. Albans, UK.

Singh, S. D. 1967. On two new species of the genus Aphelenchoides Fischer, 1894 (Nematoda: Aphelenchoididae) from North India. J. Helminthol. 41:63-70.
Singh, S. P. 1977. Aphelenchoides wallacei sp. n. and Aphelenchoides jonesi sp.n. (Nematoda: Aphelenchoididae) from inside the roots of papaya and eggplant. Indian J. Nematol. 5:207-213.

Steiner, G., and Buhrer, E. M. 1932. Miscellaneous notes on nemic diseases. Pl Dis. Reptr 16:137.

Suryawanshi, M. V. 1971. Studies on Aphelenchoidea (Nematoda) from Marthwada, India, with descriptions of three new species and a discussion on the validity of Aphelenchus radiciculus (Cobb, 193) Steiner, 1931 Nematologica 17:417-427.

Swofford, D. L. 2003. PAUP*: Phylogenetic analysis using parsimony (*and other methods), version 4.0b 10. Sinauer Associates, Sunderland, Massachusetts.

Thompson, J. D., Gibson, T. J., Plewniak, F., Jeanmougin, F., and Higgins, D. G. 1997. The CLUSTAL X windows interface: flexivel strategies for multiple sequence alignment aided by quality analysis tools. Nucleic Acids Res. 25: 4876-4882.

Wang, Z., Bert, W., Gu, J., Couvreur, M., and Li, H. 2019. Aphelenchoides medicagus n. sp. (Tylenchina: Aphelenchoididae) found in Medicago sativa imported into China from the USA. Nematology 21:1-15.

Ye, W., Giblin-Davis, R. M., Braasch, H., Morris, K., and Thomas, W. K. 2007. Phylogenetic relationships among Bursaphelenchus species (Nematoda: Prasitaphelenchidae) inferred from nuclear ribosomal and mitochondrial DNA sequence data. Mol. Phylogenet. Evol. 43: 1185-1197.

Young, T. W. 1954. An incubation method for collecting migratory endo-parasitic nematodes. Pl. Dis. Reptr. 38:794-795.

Zhuo, K., Cui, R., Ye, W., Luo, M., Wang, H., Hu, X., and Liao, J. 2010 Morphological and molecular characterization of Aphelenchoides fujianensis n. sp. (Nematoda: Aphelenchoididae) from Pinus massoniana in China Zootaxa 2509:39-52 